This is the Author's Accepted Manuscript version, uploaded in accordance with the publisher's self-archiving policy. Please note: this is the author's version of a work that was accepted for publication in FUEL PROCESSING TECHNOLOGY. Changes resulting from the publishing process, such as editing, structural formatting, and other quality control mechanisms may not be reflected in this document. The definitive version is available at:

http://dx.doi.org/10.1016/i.fuproc.2015.06.034

\title{
Assessment on bulk solids best practice techniques for flow characterization and storage/handling equipment design for biomass materials of different classes
}

Diego Barletta ${ }^{a *}$, Robert J. Berry ${ }^{b}$, Sylvia H. Larssonc ${ }^{c}$, Torbjörn A. Lestanderc, Massimo Poletto ${ }^{\text {, Álvaro }}$ Ramírez-Gómez ${ }^{\mathrm{d}}$

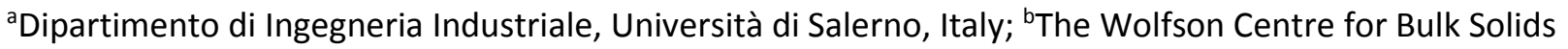
Handling Technology, The University of Greenwich, Chatham, UK; 'Swedish University of Agricultural Sciences, Department of Forest Biomaterials and Technology, Division of Biomass Technology and

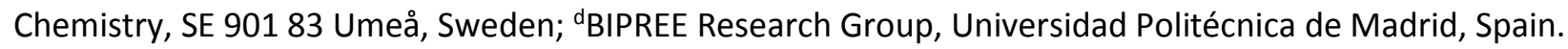

*Corresponding author. Phone: +39089962499 E-mail: dbarletta@unisa.it

\begin{abstract}
This paper shows the results of a collaborative project in which four different laboratories have carried out complementary characterization tests on samples of the same set of lignocellulosic biomass materials with the objectives of better understanding their properties and identifying any critical features of the different characterization procedures. Three different types of material were used as model biomasses: 1) Scots pine wood chips, as an example of a coarse and flaky particulate biomass with some elastic properties; 2) chopped straw of reed canary grass as a nesting biomass having long and flaky fibers; 3 ) Scots pine wood powder as a fine particulate with elastic and cohesive properties. Particle size and shape analyses were carried out with; calipers, 2D image analysis, 3D image analysis (ScanChip) and through mechanical sieving. Applications and validity limits of each of these techniques are evaluated and discussed. The flow function and internal friction
\end{abstract}


were determined with a Schulze ring shear tester, a Brookfield powder flow tester and a large ring shear tester. No significant differences in the results generated by these shear testing techniques were found. Wall friction measurements were carried out with a Schulze ring shear tester; a Brookfield powder flow tester; a large Jenike shear tester and a Casagrande shear box. Results, in this case, showed significant differences with a higher wall friction coefficient obtained with the larger shear cell. Additionally, tensile strengths of biomass materials were measured by the use of a novel measurement technique. Arching tests were carried out in a pilot scale plane silo with variable hopper geometry and results were compared with those predicted by applying the Jenike procedure and a modified procedure which assumed tensile strength was the controlling material property (rather than unconfined yield strength). Finally, safety of handling and storage was assessed by carrying out explosion tests on dusts from Scots pine and reed canary grass.

KEYWORDS: lignocellulosic biomass, particle size, particle shape, flowability, arching, explosion

\section{RESEARCH HIGHLIGHTS:}

- Suitable test methods were classified for three biomass classes

- Different particle sizing methods give a wide range of results

- Shear tests do not discriminate flowability differences between the biomass classes

- Arching behavior depends more on tensile strength than on compressive strength

- Scots pine and reed canary grass dusts are flammable

\section{Introduction}

The interest in solid biomass has been increasing over the last decades for their potential as renewable energy sources and as raw material for biorefineries, producing a great variety of added-value products in well integrated production chains [1-3]. Industrial use of lignocellulosic biomass implies an increase in 
demand for robust and reliable bulk solids handling. When compared with liquid processing plants, those involving the use of solids are characterized by significantly longer start up times, larger start up costs and by plant through-puts which may be significantly reduced with respect to their design value [4]. Furthermore, lignocellulosic biomass feedstocks are inherently variable including; the raw materials, by-products, residuals, and wastes. There are differences between plant species but also in structural elements within individual plants (e.g. phloem, xylem, bark, leaves/needles, roots, fruits etc.) adding more variation to physical and chemical properties [5], besides that of moisture content and potential contaminants. Moreover, mechanical and thermal pretreatments before feeding to conversion plants can significantly change the properties of biomass solids. In particular, milling [6-8], densification $[9,10]$ and thermal treatment [11 - 13] affect particle size and shape distribution, bulk density and energy density. With specific reference to solids from particulate biomasses, handling and feeding present further difficulties due to peculiar properties both at particle level and at bulk level that make these materials even more unpredictable than other granular materials traditionally processed by industry, especially in terms of flow reliability and control [14-16]. As a result these materials often require a semi-empirical approach to correlate discharge and flow property data with composition $[17,18]$. Robust and reliable characterization methods for off-line measurements of particulate biomass flow properties are urgently needed, as well as biomass structure and composition characterization methods, suitable for on-line analysis of rapid material streams enabling fast non-destructive biomass classification procedures, e.g. spectrometry [19-21].

Flow problems can be correctly addressed through knowledge of flow properties of bulk solids and by the availability of reliable design methods for industrial silos. However, standard characterization methods used for flow properties of common granular solids are not always suitable for biomass materials. A significant problem is that conventional shear testers have been mainly developed for measuring frictional and cohesive properties of bulk solids with non-fibrous rigid and generally homogeneous particle shapes as well as with particle top sizes below a few millimeters [22-24]. Few biomass materials have particle size, stiffness and shape distributions that meet these requirements. Thus, for large biomass particles one possibility is to use a larger scale shear tester [25]. However, for biomass materials that consist of elongated particles or fibers, like straws and grasses, there are more fundamental questions regarding the validity of shear testing as a 
characterization technique. These materials are highly compressible and comprise particles that are severely entangled, hindering the formation of a well-defined shear zone and the attainment of steady state flow conditions [26-28]. Moreover, preliminary studies indicate that tensile strength could be a more relevant flow property than compressive strength due to mechanical interlocking caused by entanglements between fibrous solids [29]. These observations indicate that there is a need to more deeply assess both the validity of elasto-plastic constitutive models and the choice of suitable testers for the characterization of the flow properties of biomass particulate solids.

In addition to this, common design methods for storage units to ensure flow, based on Jenike analysis [30], have not yet been proven to work for biomass bulk solids. The tendencies of different biomasses to arch or bridge across hopper outlets has been investigated in several studies. Flat bottomed containers with an opening slot were initially used to experimentally derive the critical outlet size for arching as a function; of particle size distribution, particle shape and moisture content of the biomass sample [31-34]; of air promotion flow [35] or of the milling procedure [36], but without considering consolidation stresses. A similar apparatus based on the same method was also recently proposed as a reference method for European standardization [37]. However, the applicability of these results to larger (real scale) silos and to conical or wedge-shaped hoppers has not been proven. A clue to the effect of increasing vessel size (and hence increasing magnitude of consolidation stress) is provided by the observation that the critical arching dimension increases as the filling level of biomass in the vessel is rising [31, 34]. The role of consolidation stress has been confirmed by arching tests on biomass beds compacted by an external load [38, 39]. Barletta and Poletto carried out a direct assessment of the Jenike design method performing experiments on a wedge shaped hopper $[40,41]$. Results from these studies indicate that the design procedure is adequate for the tested wood powder samples in a hopper with a capacity of about $0.3 \mathrm{~m}^{3}$. However, further investigations are needed to complete the assessment, for a wider range of materials and to better understand the effect of the consolidation stress magnitude (related to bed height and container diameter) on the arching behaviour and the critical outlet size. 
Furthermore, safety issues related to dust generation during [42] biomass handling need to be addressed. Fires (due to self-heating during storage) and dust explosions are two important issues in biomass bulk handling, because they may result in worker injuries, loss of life, considerable economic costs and environmental damage. A dust explosion is the result of rapid combustion of fine particles dispersed in air. In the presence of an ignition source they react with oxygen, generating an exothermic chain of reactions. If these reactions occur inside a vessel the system pressure increases rapidly [43, 44]. Under these circumstances, venting devices are designed to release pressures, and indeed, as protection measures usually are the only options. Explosion pressures can reach 7-10 bar in a closed vessel with no protective system. Considering that walls and roofs of typical biomass containers are not designed to bear such pressures, explosions may lead to serious structural damages, including complete silo destruction. The most significant parameters characterizing the violence of an explosion are the maximum pressure reached $\left(P_{\max }\right)$ and the maximum rate of pressure rise $\left(K_{s t}\right)$. However, there is a lack of data concerning these parameters for biomass materials. Still, the majority of reported industrial explosions had their origin in organic (carbon) dusts that have compositional similarities with biomass materials, which suggests that these materials present a significant explosion risk.

This paper shows the results of a collaborative project (Bio4Flow) in which four different laboratories have carried out complementary characterization tests on three sets of biomass samples with the purpose of better understanding their material properties and highlighting possible critical features of biomass characterization procedures. The laboratories involved are:

- $\quad$ the Biofuel Technology Centre at the Swedish University of Agricultural Sciences, Sweden (SLU BTC);

- the Wolfson Centre for Bulk Solids Handling Technology at the University of Greenwich, United Kingdom (UG Wolfson);

the Powder Technology Group of the University of Salerno, Italy (US PTG);

the BIPREE Research Group of the Technical University of Madrid, Spain (UPM BIPREE). 


\section{Materials and Methods}

\subsection{Materials}

Three material assortments were chosen to represent common types of biomass bulk solids: wood chips, wood powder, and straw chops. Scots pine (Pinus sylvestris L.) wood chips (Figure 1a) with particle sizes of approximately $<25 \times 15 \times 5 \mathrm{~mm}$ and a moisture content of $10-15 \%$ (wet basis) were obtained from a sawmill (Sävar såg, Sävar, Sweden). Wood powder (Figure 1b) was produced from the wood chips assortment through hammer milling (Vertica Hammer Mill DFZK-1, Bühler AG, Uzwil, Switzerland) using a screen size of 4 mm. Straw chops with a moisture content $10-15 \%$ (wet basis) was produced from reed canary grass (RCG) (Phalaris arundinacea L.) and shredded in a single shaft shredder (Lindner Micromat 2000, Lindner-Recyclingtech $\mathrm{GmbH}$, Spittal, Austria) with a $40 \mathrm{~mm}$ screen size (Figure 1c).

Different methods were used to characterize these biomass materials. The methods are presented in the following sections. Table 1 provides a summary of the methods adopted.

\subsection{Particle size distribution measurement methods}

Particle size distributions and shapes were measured with the following techniques (also listed in Table 2):

\section{Sieve analysis}

Particle size distributions of wood chips and straw chops were determined with an oscillating screen method according to the European standard for determination of particle size distribution of solid biofuels with particle sizes $>3.15 \mathrm{~mm}$ [45]. The wood powder particle size distribution was determined with a vibrating screen method according to the European standard for determination of particle size distribution of solid biofuels with particle sizes $<3.15 \mathrm{~mm}$ [46]. Sieve analyses were assumed to provide a measure of the particle width.

\section{D image analysis}

The particle size distribution via 2D image analysis [47] was carried out only on samples of the biomass types with larger particles, i.e. wood chips and RCG straw. This procedure, in fact, includes hand preparation of samples which was impractical for the fine wood powder particles. 
The first operation was the powder sampling. A sample of about $100 \mathrm{~g}$ of the powder was scooped from three positions in the bag. The sample was gently mixed and divided into four wood chips and sixteen RCG portions. In both cases, each single portion was weighed and then sieved on a standard ASTM (American Society for Testing and Materials) screen with a $2 \mathrm{~mm}$ aperture size. The obtained samples were spread out on a black A4 paper sheet over the plane of a photographic bench. A caliper ruler was placed at one side of the sheet, in order to calibrate images. The photographic bench was equipped with 4 lamps (incandescent bulbs with a power of $250 \mathrm{~W}$ each) connected to a DC supply to avoid light fluctuations. Digital pictures were taken with a Nikon D100 Camera (Nikon Co, Tokio, Japan), equipped with standard Nikkor $50 \mathrm{~mm}$ focal length lenses. Digitized images were analyzed with the help of Image-Pro Plus Software of the Media Cybernetics, Inc (Rockville, MD USA). After calibrating the image with the ruler and selecting an area of interest which excluded image borders, the built in procedure "count/size" was run. Selected particle measurements were:

- Particle projected area, $A\left[\mathrm{~mm}^{2}\right]$

- Maximum diameter $\left[\mathrm{mm}^{2}\right]$, i.e. the longest line joining two points of the object outline and passing through the centroid

- Minimum diameter $\left[\mathrm{mm}^{2}\right]$, i.e. the shortest line joining two points of the object outline and passing through the centroid

- Major axis $\left[\mathrm{mm}^{2}\right]$, i.e. the length of the major axis of an ellipse with the same moments of order 1 and 2 order as the particle image

- Minor axis $\left[\mathrm{mm}^{2}\right]$, i.e. the length of the minor axis of an ellipse with the same moments of order 1 and 2 order as the particle image

- Particle roundness [-], defined as $P^{2} /(4 \pi A)$, where $P$ is the perimeter [mm] of the projected particle image, i.e. the ratio of the area of a circle having the perimeter of the projected particle over the particle projected area

From these measurements other quantities were obtained, namely:

- Particle equivalent diameter [mm], i.e. the diameter of the circle having the same projected area as the particle

- Particle elongation ratio [-], i.e. the ratio of the maximum axis over the minimum axis. 
- Size ratio [-], i.e. the ratio of the maximum diameter over the minimum diameter.

Tabular outputs of the "count/size" Image-Pro Plus procedure were exported to a spreadsheet file to collect the results of more images. To analyze about $60 \mathrm{~g}$ of wood chips, 8 images were used for a total count of about 1100 particles. To analyze about $4.2 \mathrm{~g}$ of RCG, 7 images were used for a total count of about 8800 particles.

For each material, all data collected on the Excel file was ordered and grouped in order to obtain experimental cumulative distributions.

\section{D image analysis}

Length, width and thickness of single particles were scanned with resolution of $0.22 \times 0.22 \times 0.17 \mathrm{~mm}$ using a ScanChip analysis system for optical measurement (Andritz, Iggesund Tools, Iggesund, Sweden). This device uses vibratory conveyors to separate particles from each other before measuring particle dimensions at a calibrated speed on a transport band by a laser-supported camera and laser triangulation. In this study, the system was set to measure particles with thickness $>1 \mathrm{~mm}$.

\section{Caliper}

A pair of digital Vernier calipers was used to manually measure the approximate length, breadth and thickness of a cuboid around the particles (to the nearest $0.5 \mathrm{~mm}$ ). Note that due to the elasticity and fragility of the particles the micrometer was lined up to the respective dimension by eye, rather than by gently tightening the jaws, as it is usually done for solid objects. Measurements were taken on small samples of each biomass type cut at a particle size above $2 \mathrm{~mm}$. Fines were not measured due to the difficulties involved in manual handling.

\subsection{Flow properties test methods}

\subsubsection{Internal flow properties}

Internal flow properties of materials were tested with different equipment and methods. These are described in the following: 


\section{Schulze Ring Shear Tester - RST}

Yield loci measurements for straw chops and wood powder particles were made with a Schulze [48] ring shear tester RST-01.01 (Dr. Dietmar Schulze Schüttgutmesstechnik, Wolfenbüttel, Germany) according to the ASTM standard [49]. Materials were sheared at four different consolidating stresses (ranging from 4.6 to 20.9 $\mathrm{kPa}$ ). It was not considered meaningful to take measurements for wood chips due to too large particle sizes.

\section{Brookfield Powder Flow Tester - PFT}

The Brookfield powder flow tester (PFT) is an automated annular shear tester as described in [50]. The main specification is as follows; the powder is stored in an annular trough of inner and outer diameters 100 and $150 \mathrm{~mm}$, respective, and depth $19 \mathrm{~mm}$. The trough is enclosed by an annular lid of the closed pocket design after Walker [51] where the 18 lid pockets are formed by a radius cavity with equally spaced vertical vanes.

The sample is consolidated and failed by applying a torsional load by rotating the trough while a controlled axial is applied through the lid. The rotational speed of the trough is one revolution per hour, the normal stress range of the machine is 0.3 to $4.8 \mathrm{kPa}$. The sampling frequency for the axial and torsional loads is $50 \mathrm{~Hz}$.

The shear test algorithm followed is essentially similar to the one described in ASTM 6128 for the Jenike shear tester. The key difference is the inclusion of shear stress peak at the consolidation normal stress in the failure locus construction.

\section{Large Annular Shear Tester - LAST}

The large annular shear tester (LAST) at Wolfson Centre is a large manually operated annular (or ring) shear tester. Outer and inner diameters of the trough are $1 \mathrm{~m}$ and $0.75 \mathrm{~m}$, respectively. The trough depth is 0.15 m. The annular lid is of the open pocket design [48] where the underside of the lid is flat, with pockets formed by 18 evenly spaced vertical vanes with sides that are open.

The $52 \mathrm{~kg}$ lid is suspended from its centre on a counter balance beam. The desired consolidation load is achieved by applying dead weights to the lid or counter balance. To shear the sample, the trough is slowly rotated at ( $1 \mathrm{rev} / \mathrm{hr}$ ) while the rotation of the lid is prevented by a torque arm connected to load cells by a 
pair of tie bars. The normal stress range is low due to the large normal loads required on the large area of the lid.

The test algorithm followed manually is the same as that described above for the PFT.

\section{Tensile tester - TT}

The tensile tester (TT) is at present a prototype for proving the principal and still requires significant refinement. The tester comprises a pair of identical rectangular cells with a vertical split down the centre (with the permission of Rob it would be interesting to introduce Figure XX).

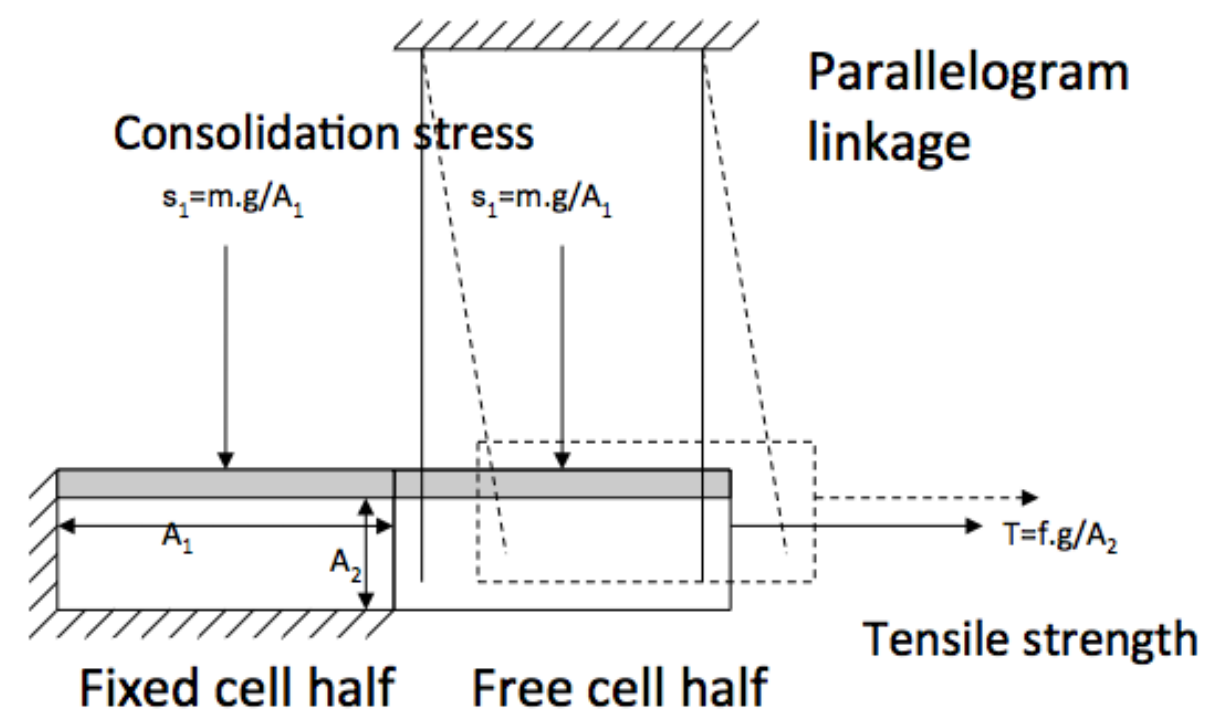

The cells are clamped together and the extreme shape biomass evenly filled into the cell and leveled. A pair of independent lids and dead weights is applied to the top free surface of the biomass in the two cell halves to generate the required normal stress. To enable tensile failure of the sample, one cell half is fixed to the frame of the machine while the other half is suspended from the frame via four wires in the form of a parallelogram linkage. On the end of this moving cell half, a horizontal cord passes over a pulley to a weight hanger. With a given normal load acting on the sample, increasing horizontal tensile loads can be applied by increasing dead weight on the pulley until failure and separation occur. Only the peak load is measured. As 
the cell is on a parallelogram linkage the vertical component of the force must be subtracted to determine actual horizontal force at failure. The height of the sample at failure is measured to determine bulk density and the area of the tensile failure plane. The data is presented as a tensile strength function i.e. tensile strength as a function of uniaxial consolidation stress. The consolidation stress range of the equipment is approximately from 0.2 to $3 \mathrm{kPa}$.

\subsubsection{Wall friction properties}

Wall friction properties of materials were tested with different equipment and methods. Besides the already mentioned Schulze ring shear tester these are described in the following:

\section{Large Jenike Wall Friction - LWFT}

The large wall friction tester (LWFT) is a linear device with a $270 \mathrm{~mm}$ diameter shear ring $(20 \mathrm{~mm}$ depth) that rest on a wall sample of $300 \times 500 \mathrm{~mm}$ dimension. The biomass sample is enclosed with a compression lid. The wall normal stress range of the tester is 0.5 to $12 \mathrm{kPa}$, while the wall shear stress range is 0 to $6 \mathrm{kPa}$. Shearing is facilitated by pulling the sample along the wall. This motion is produced by a linear slide (driven by an electric pistol drill) travelling at a constant speed of $0.6 \mathrm{~mm} / \mathrm{s}$.

\section{Casagrande shear box - CG WFT}

The device used was a circular shear tester, $10 \mathrm{~cm}$ in diameter and $3 \mathrm{~cm}$ deep. Its design (Figure 2) was based on the Casagrande shear box (CG WFT) which allows relative displacement of parts of the box to be controlled $[52,53]$. Direct shear tests were used to determine the particle-to-wall friction coefficient. The cell of the direct shear apparatus was modified by inserting a steel mold as shearing surface (Figure 2).

\subsection{Arching test methods}

Discharge experiments were carried out in a plane silo (Figure 3), with a total volume of about $0.3 \mathrm{~m}^{3}$, formed by a parallel-piped bin and a wedge-shaped hopper in which it is possible to independently change both hopper steepness and width of the outlet slot. Transparent glass front and rear walls of the silo allow visual inspection of the flowing solids inventory. All the other silo walls are made of stainless steel. The adopted experimental procedure includes: i) adjustment of hopper steepness and outlet slot width; ii) loading of 
biomass from the silo top while the opening of the hopper is closed by a slab, held by a hydraulic piston; iii) biomass leveling with a rake; iv) very slow lowering of the closing slab by operating the hydraulic piston while monitoring the flow regime (flow or arcing) by photo or video recording. For each value of hopper angle, $\alpha$, within the hopper mass flow range, experiments were repeated with different outlet openings to find the maximum opening size, $D_{c}$, giving rise to stable arch formation.

\subsection{Explosion test methods}

Values defining the maximum explosion pressure $\left(P_{\max }\right)$ and the characteristic constant $\left(K_{\mathrm{st}}\right)$ for explosion class have been determined in this research work according to the current normative for explosibility characterization (UNE-EN 14034-1:2005+A1:2011). The maximum pressure $P_{\max }$ is the difference between pressure at time of ignition (normal pressure) and pressure at the highest point in the pressure-time record. The test device used was a Kühner 20-I sphere. Three series of tests were carried out, and results showed a deviation of less than $10 \%$ from the average, which is considered acceptable. The maximum explosion pressure rise $(\mathrm{d} P / \mathrm{d} t)_{\max }$ is defined as the maximum slope of the tangent to the pressure vs. time curve at each nominal fuel concentration. The characteristic constant $\left(K_{\mathrm{st}}\right)$ is obtained from the product $(\mathrm{d} P / \mathrm{d} t)_{\max }$ multiplied by the cubic root of the explosion enclosure volume. The explosion class is defined as a function of the $K_{\mathrm{st}}$ values, as follows: St0 (non-explosible) for $K_{\mathrm{st}}=0 \mathrm{mbar} / \mathrm{s}$; St1 (weak) for $K_{\mathrm{st}}=1-200 \mathrm{mbar} / \mathrm{s}$; St2 (strong) for $K_{\mathrm{st}}=201-300 \mathrm{mbar} / \mathrm{s}$; St3 (very strong) for $K_{\mathrm{st}}=300 \mathrm{mbar} / \mathrm{s}$.

\section{Results}

\subsection{Particle size distributions}

Comparisons between results for different particle size measurement methods are shown in Figure 4. Caliper measurements and 2D analysis are very work intensive. Hence, sample sizes were not as large as for sieving or 3D image analysis. Representative sampling is crucial for comparisons, but is very difficult to ensure. Results are all expressed in terms of weight fractions. Particles passing the smallest sieve aperture size of 3 $\mathrm{mm}$ were assumed to have an average size of $1.5 \mathrm{~mm}$. Length distribution of wood chips (Figure 4a) and RCG (Figure 4b) shows a good agreement between techniques except for 2D image analysis for RCG. Width 
distribution of wood chips (Figure 4c) and RCG (Figure 4d) shows that 3D and caliper as well as 2D and sieving generally match in pairs. The above discrepancy may be due to the fact that $2 \mathrm{D}$ and sieving covered the full size range, whereas manual calipers and the ScanChip instrument used for 3D analysis (which was set to detect particles larger than $1 \mathrm{~mm}$ in thickness) could not take into account finer particles. Measurements of the particle thickness could only be performed with caliper and 3D image analysis (Figure 4e for wood chips and Figure 4 f for RCG). However, it must be noted that the analysis is somewhat skewed, in fact only particles with a thickness $>1 \mathrm{~mm}$ were analyzed in the 3D data.

$2 \mathrm{D}$ analysis also provided some information on particle shape. Figure 5a presents the cumulative elongation distribution with reference to the particle projected area. RCG shows much more elongated particles than wood chips. In order to understand if the shape is somehow related to the particle size, Figure $5 \mathrm{~b}$ reports the average equivalent particle diameter in terms of equivalent projected area, for the different elongation classes used for the cumulative distribution. Inspection of results indicates that for wood chips, smaller particles are more elongated than large particles. This is probably due to fragmentation of larger particles which are preferentially separated in the fiber direction. For the RCG, contrasting results were obtained with the larger size particles being more elongated than smaller ones. This is not surprising since RCG particles are obtained through chopping at a length larger than the straw width. Furthermore, RCG particle fibers are very fragile so that breakage perpendicular to the fiber direction can also occur.

It is interesting to compare the results reported above with those provided by Guo et al. [5] even if this latter case concerns particles of much smaller size. Guo et al. [5] reported that particle elongation increased with particle size (irrespective of the biomass origin), as was found here for RCG only. Guo et al. [5] noted also that the frailest biomass materials showed a more marked correlation between particle size and particle elongation. Perhaps the different correlation between particle size and elongation found between this work and the one reported by Guo et al. [5] for wood materials might be related to the high energy intense milling procedure adopted to pulverize the fuel in [5] that may have allowed cross fiber breakage also for wood. In this work any particle breakage events resulted from low energy intensity bulk material handling operations 
(shear testing, hopper flow) that were insufficient to produce cross fiber breakage with wood, but sufficient to cause cross fiber breakage of the fragile RCG particles.

Wood powder particles were too small to be measured with 3D Scanchip, 2D image analysis, or with calipers. Therefore sieving was the only measurement available for this powder as reported in Figure 6. In particular, laser diffraction was applied only to the cut obtained after sieving by a $1400 \mu \mathrm{m}$ sieve. The cumulative particle size distribution reported was calculated taking into account the volumetric fraction under and over 1400 $\mu \mathrm{m}$.

\subsection{Flow properties}

The flow properties were measured using a range of shear testers, namely the Brookfield PFT, Schulze RST, the Casagrande shear box (CG WFT), the Wolfson Centre large annular shear tester (LAST) and large wall friction tester (LWFT) as well the tensile tester (TT). The full size RCG was tested in the large cells while fines were tested in the standard testers. For wood powder, the full size range was tested on all machines, while only the large cells were capable of testing the wood chips.

Extreme shape materials do not develop a shear plane (coincident with the underside of the lid) when exposed to extended torsional displacement in the cell. However, due the irregular particle shape and ability to interlock, extended shear also causes the material to be redistributed in the lid pocket rather than simply shear (see Figure 7). Material at the back of the pocket does not move, and thus, as the lid rotates, the length of the powder sample contained in the pocket gets shorter and increases in height causing a lifting of the lid and formation of a void at the back of the pocket. Thus, the assumption of stresses being uniformly applied over the cross sectional area of the cell are no longer valid and actual normal stress is significantly higher than that inferred by the load over the cell area. This is similar to the behaviour seen with cohesive powders if a large number of vanes are removed from the cell, i.e. suggesting that for high internal friction materials, like fibrous biomass, a shearing lid with more vanes is necessary to grip the powder and cause shear. Or simply, this is a sign that these materials do not shear and, therefore, an alternative approach is required to characterise their strength. This behaviour is evidenced by the shear stress vs. shear strain traces which 
shows an under-consolidated response to torsional displacement with the shear stress rising slowly and never reaching consolidation due to the relative movement of the material in the shear cell. Figure 8 shows an example of this behaviour compared with that of sand, a conventional particulate material.

Inspection of the biomass flow functions of wood chips (Figure 9), RCG (Figure 10) and wood powder (Figure 11) shows that all would be classed as easy flowing/cohesive materials, with fair agreement between different shear testers. Manual handling suggests that the flaky wood chips are elastic/free-flowing, the fibrous RCG exhibits nesting behavior, and the wood powder is an elastic/cohesive material. The problem is the relevance of shear testing to fibrous/flaky particulates that do not shear, as demonstrated by internal frictions in the Figures 9 to 11 , showing large variations in angle $\approx 10^{\circ}$ for the fibrous RCG and flaky woodchips. The tensile tester (Figure 12) detected significant differences, with wood powder having no measureable strength whereas the fibrous and elongated RCG entangled together and showed the greatest tensile strength. Wall friction data for all three materials (Figure 13) showed that the LWFT, with a larger, and thus, more representative surface area than the other methods, showed significantly higher friction coefficients than the Brookfield PFT, Schulze RST, and Casagrande shear box for the three materials tested.

\subsection{Arching tests}

In arching tests, hopper inclination, $\alpha$, was chosen to be steep enough to ensure mass flow conditions during material discharge. For each hopper inclination, the minimum outlet size preventing formation of a stable arch of bulk material at the outlet was experimentally determined. Experimental data for the three materials (reported in Figure 14 as hollow symbols) show critical outlet sizes between 0.02 and $0.28 \mathrm{~m}$. Critical outlet sizes were generally increasing in this order: wood powder, RCG, wood chips. This ranking does not correspond to the flowability classification obtained from shear test derived flow functions and the discrepancy may only be partly explained by the different bulk density values that also play a significant role in the arching test.

Results confirm that the arching propensity of different types of biomass cannot be explained solely by unconfined yield strength characteristics. Critical outlet size values, $D_{c}$, were also calculated according to the 
hopper design procedure of Jenike [54], as reported also by Cannavacciuolo et al. [35]. Following this procedure, when the arch is on the verge of collapsing, its weight is just balanced by the vertical component of the maximum normal stress close to the walls. Jenike and Leser [55] derived inequality (Eq. 1) from the force balance on the arch and by assuming that the arch is unstable if material resistance is lower than the abutment stress:

$$
f_{\mathrm{c}}<\frac{\rho_{\mathrm{b}} g D}{H(\alpha)}
$$

where $f_{\mathrm{c}}$ is the unconfined yield strength of the powder in use, $D$ is the effective outlet size, $\rho_{\mathrm{b}}$ is the powder bulk density, $g$ is the acceleration due to gravity, $H(\alpha)$ is a function which takes into account effects of variation of thickness of the arch with the silo geometry and the hopper half-angle $\alpha$. Jenike and Leser [55] reported a graphical solution of $H(\alpha)$ that is well approximated by the following equation [56]:

$$
\frac{1}{H(\alpha)}=\left(\frac{65}{130+\alpha}\right)^{i}\left(\frac{200}{200+\alpha}\right)^{1-i}
$$

where silo geometry is accounted for by the exponent $i, i=0$ for wedge hoppers and $i=1$ for conical hoppers. In mass flow silos, consolidation stress at outlet, $\sigma_{1}$, depends on distance from virtual hopper vertex. According to Jenike [54], it is possible to show that:

$$
\sigma_{1}=\rho_{\mathrm{b}} g D \frac{\left(1+\sin \phi_{\mathrm{e}}\right) s\left(m, \alpha, \phi_{\mathrm{e}}, \phi_{\mathrm{w}}\right)}{2 \sin \alpha}
$$

where $s$ is a complicated function depending on hopper geometry (wedge or conical), on its half angle, $\alpha$, on the tensional state ( $m=1$ for active state, $m=-1$ for passive state), on powder effective angle of internal friction, $\phi_{e}$, and on powder wall friction, $\phi_{w}$. Combining Equations (1) and (3) it is possible to obtain the free flow criterion to be applied on the plane $f_{\mathrm{c}}-\sigma_{1}$ :

$$
f_{\mathrm{c}}<\frac{\sigma_{1}}{f f}
$$

where $f f$ is the flow factor 


$$
f f=H(\alpha) \frac{\left(1+\sin \phi_{\mathrm{e}}\right) s\left(m, \alpha, \phi_{\mathrm{e}}, \phi_{\mathrm{w}}\right)}{2 \sin \alpha}
$$

Diagrams reporting flow factors for conical and wedge hopper are given by Jenike [30] for different values of; $\alpha, \phi_{\mathrm{e}}$ and $\phi_{\mathrm{w}}$. Flow factor estimates can also be obtained by using the mathematical procedure proposed by Arnold et al. [57]. The flow factor line, determined by the LHS term of Equation (5), generally cuts in two parts the powder flow function $F F$, that is the experimental material constitutive equation in which unconfined yield stress $f_{\mathrm{c}}$ is given as a function of consolidation stress $\sigma_{1}$ :

$$
f_{\mathrm{c}}=F F\left(\sigma_{1}\right)
$$

The intersection between the flow function and the line representing the flow factor provides the critical unconfined yield strength of the material, $f_{\mathrm{c}}{ }^{*}$. The smallest outlet size, $D_{\mathrm{c}}$, providing arch free flow is given by:

$$
D_{c}=\frac{f_{\mathrm{c}}^{*} \cdot H(\alpha)}{\rho_{\mathrm{b}} g}
$$

In fact, in agreement with Eq. (1), $D$ values larger than $D_{c}$ provide arch free flow of powders. According to the design theory presented above, the flow properties reported in the previous section were used to evaluate design values reported in Table 3. Values of $H$ functions and flow factors were evaluated according to Arnold and Mc Lean [56]. The intersection of flow factor, $f f$, and flow functions lines (FF), for each material and shear testing method, determined critical values of the unconfined yield strength $f_{c}{ }^{*}$ which, in turn, were used in Eq. (7) to determine theoretical values of $D_{c}$. Design values of $D_{c}$ are compared with experimental data in Figure 14. Comparison shows that design values largely overestimate critical sizes for all biomass materials. Flow properties data obtained by different shear testing techniques significantly affected the design values of $D_{\mathrm{c}}$. However, the discrepancy between experimental values and design values does not seem to be fully explained by this uncertainty. Additional reasons might be related to the main assumptions of the Jenike analysis (Coulomb solid, radial stress field, balance between material compressive strength and stresses internal to the arch) whose validity for biomass materials needs a deeper assessment. For fibrous biomass materials it can be argued that arch stability is related to bulk material tensile strength, $\sigma_{\mathrm{t}}$, as it was measured 
in section 3.2 above, rather than bulk material unconfined compressive yield strength. In fact, the material in the arch might not be supported by cohesion which provides the material strength under unconfined conditions, but because the material in the arch is connected to the upper layer of material inside the silo by the effect of bulk tensile strength. Without undertaking a rigorous force balance, dimensional analysis suggests that an order of magnitude evaluation of $D_{c}$ can be expressed as:

$$
D_{c} \cong \frac{\sigma_{\mathrm{t}}}{\rho_{\mathrm{b}} g}
$$

For RCG at low hopper angles and for wood chips within the entire hopper angle range, values of $D_{\mathrm{c}}$ calculated according to Eq. (8), reported in Figure 14, show better agreement with experimental data. Nonetheless, the role of bulk tensile strength on the arching stability of biomass materials will deserve a thorough study before the adoption of a procedure such as the one suggested with Eq. (8) can be reliably employed.

\subsection{Explosion tests}

Dust was separated from the original sample of wood powder and of RCG by sieving. The Scots pine dust has $80 \%$ of the volumetric particle size distribution between 47 and $378 \mu \mathrm{m}$ and a moisture content of $8.4 \%$ by weight. The RCG dust has $80 \%$ of the volumetric particle size distribution between 19 and $279 \mu \mathrm{m}$ and a moisture content of $8.1 \%$ by weight. Dust explosion classes according to the $K_{\mathrm{st}}$-value reveal that handling of Scots pine and RCG presents a dust explosion hazard like other organic materials, i.e. coals. For the sake of comparison, lignite was selected as a reference material [44] (Table 4). Although RCG and wood powder from Scots pine fell into the lowest explosive class (the studied biomass are classified as St1), this does not necessarily indicate a lower level of hazard. In fact, some of the most devastating dust explosions in the process industry have occurred with dusts in the lower ranges of the St 1 class [58].

\section{Discussion}

Table 5 summarizes characterisation methods appropriate for each of the three biomass materials considered. An $\mathrm{X}$ in the table indicates the possibility to use that method on a specified material. For size measurements a sequence of characters is used including L, W and T indicating the possibility to measure 
particle length, width and thickness, if appropriate. The three different material tested present different characteristics which make different measurement procedures more or less appropriate. These will be discussed in the following for each of the materials. Firstly, for the tested materials they all produce fines which have to be properly accounted for to correctly evaluate the explosion risks.

\subsection{Wood chips}

Wood chips appear as a flaky free flowing material characterized by large particles, although this material can bring a certain portion of fines. Particle size distribution can be measured in a meaningful way with all techniques proposed, except laser diffraction. 3D image analysis is particularly interesting, due to the completeness of information provided and for the rapid measurement procedure. Some care is required however to account for correct contribution especially with reference to width and thickness distributions. Regarding the width, sieving is the fastest and most accurate procedure. However, this technique cannot provide any information regarding other shape characteristics. Shape distributions obtained with $2 \mathrm{D}$ analysis clearly indicate the tendency of this material to break along the fiber length.

Since wood chips are characterized by relatively coarse particles, not all powder flow testers can be used to carry out powder flow measurements. It has been observed that shearing of this material in a shear cell does not lead to the formation of a defined shear plane of known surface, and that this uncertainty might impair the final measurement results. However, given these limits, internal flow properties obtained with the large shear tester and the ring shear tester are almost equivalent. This was not the case for wall friction measurements, for which a large shear tester provides higher values compared to standard size equipment. In this case, in fact, standard size testers may provide lower wall friction angles which could lead to underdesigned storage unit dimensions.

The critical hopper outlet size for wood chips predicted with the Jenike [54] procedure, using data both from conventional and large testers are in all cases extremely conservative. Instead, as indicated in Figure 14 a, arch stability in the silo flow experiments is better described by the material tensile strength. 


\subsection{Reed canary grass (RCG)}

RCG appears as a flaky nesting material characterized by large and very flat and frail particles which produce a significant amounts of fines. Particle size distribution can be measured with all the techniques proposed, except laser diffraction. Also here, 3D image analysis is particularly appropriate for the completeness of the information provided and for the rapid measurement procedure but care is required to account for the correct contribution of fines. With reference to particle width, sieving is the fastest and most accurate procedure. However, this technique cannot provide any information of other shape characteristics. Further, sieving of straw materials is challenging due to particle nesting and, when treated for longer time periods, brittle materials may break into pieces. Shape distributions obtained with the 2D analysis clearly indicate a tendency for this material to break across the length of the fibers. Therefore, fines show a less elongated shape.

With RCG, all powder flow testers can be utilized. However, in the same manner as for wood chips, flaky and long particles may not produce the generally assumed features of formation of a defined shear plane with known surface area. Shear tests and wall shear tests showed the same trends of similarities and dissimilarities as for wood chips.

Also for RCG, the critical hopper outlet size estimated with the Jenike [54] procedure was found to be extremely conservative. In particular, arch stability and silo flow was found to depend more on tensile strength properties than shear test data at low hopper angles. Arch stability depending on unconfined yield strength estimated from RST provided a better agreement with experimental data at higher hopper angles.

\subsection{Wood powder}

Wood powder appears as an elastic cohesive material characterized by fine needle shaped particles. Particle size distribution can be measured with techniques able to measure large amounts of small particles, including laser diffraction. Among the methods tested, only sieving and laser diffraction were suitable. Unfortunately these techniques cannot provide information on the particle shape and its distribution. 
All powder flow testers are suited to carry out wood powder flow measurements. As for wood chips and RCG, the same pattern of result consistency between different shear testers was found. Also with wood powder, the large shear cell gave higher wall friction values than small shear cells did.

Arching behavior of wood powder, predicted with the Jenike [54] procedure with data from conventional and large testers, was extremely conservative. However, since wood powder shows no measurable tensile strength, the critical silo outlet size cannot be predicted by measurement of this property.

\section{Conclusions}

Particle size measurements using calipers, 2D image analysis, 3D image analysis, and sieving, gave a wide range of results. Measurements with calipers as well as 2D and 3D image analysis are suitable only for materials made of relatively large particles and still the number of particles analyzed over time might be a limitation but are powerful instruments for providing significant particle shape information.

The different shear tester measurements for the determination of flow function and internal friction could not discriminate between the three biomass materials. Larger differences in results from different testers were found for wall friction when compared to flow function results. Arching tests (in storage vessel with a capacity of about $0.3 \mathrm{~m}^{3}$ ) revealed that the critical outlet size was over-predicted by applying the Jenike [54] procedure with unconfined yield strength data. The tensile tester measured significant strength differences between the materials that were consistent with experimental arching behavior. However, the above arching test results were limited by the small scale of the hopper used, while for a conventional particulate solid the critical arching dimension is independent of the vessel size, results from $[31,34,38,39]$ suggest that this is not the case for elastic, flaky and fibrous biomass materials. Further work is therefore urgently required to better understand the relationship between vessel size; fill height and or diameter on the arching behavior, to assist with the development of a reliable design procedure for gravity discharge.

Scots pine and RCG dust are classified as St1, being flammable and, when mixed with air, being able to form an explosive atmosphere. 
The different test methods were evaluated with respect to their ability of relevant characterization of each of the three representative biomass materials tested (Table 5).

\section{Acknowledgements}

The authors are grateful to Processum Biorefinery Initiative AB for partially funding this work. We also thank Bio4Energy, a strategic research environment appointed by the Swedish government, for supporting this work.

\section{References}

[1] Committee on Biobased Industrial Products, National Research Council. Biobased Industrial Products: Priorities for Research and Commercialization, National Academic Press, Washington D.C.; 2000. ISBN: 9780-309-05392-1

[2] Kamm, B., Kamm, M., Gruber, P. R. and Kromus, S. Biorefinery Systems - An Overview, in BiorefineriesIndustrial Processes and Products: Status Quo and Future Directions (eds B. Kamm, P. R. Gruber and M. Kamm), Wiley-VCH Verlag GmbH, Weinheim, Germany, 2005

[3] Giuliano, A., Cerulli, R., Poletto, M., Raiconi, G., Barletta, D. Optimization of a multiproduct lignocellulosic biorefinery using a MILP Approximation. Comput. Aided Chem. Eng. 2014; 33: 1423-1428.

[4] Merrow, E.W., Philips, K.E., Myers, C.W. Understanding cost growth and performance shortfalls in pioneer process plants: Rand Corporation; 1981.

[5] Guo Q., Chen X., Liu H. Experimental research on shape and size distribution of biomass particle. Fuel, 2012, 94: 551-555.

[6] Gil, M., Arauzo, I. Hammer mill operating and biomass physical conditions effects on particle size distribution of solid pulverized biofuels. Fuel Process. Technol., 2014; 127: 80-87. 
[7] Cardoso, C.R., Oliveira, T.J.P., Santana Junior, J.A., Ataíde, C.H. Physical characterization of sweet sorghum bagasse, tobacco residue, soy hull and fiber sorghum bagasse particles: Density, particle size and shape distributions. Powder Technol., 2013; 245: 105-114.

[8] Alonso-Marroquín, F., Ramírez-Gómez, A., González-Montellano, C., Balaam, N., Hanaor, D.A.H., FloresJohnson, E.A., Gan, Y., Chen, S., Shen, L. Experimental and numerical determination of mechanical properties of polygonal wood particles and their flow analysis in silos. Granul. Matter, 2013; 15: 811-826.

[9] Ramírez-Gómez, Á., Gallego, E., Fuentes, J.M., González-Montellano, C., Ayuga, F. Values for particle-scale properties of biomass briquettes made from agroforestry residues. Particuology, 2014; 12: 100-106.

[10] Segerström, M., Larsson, S.H. Clarifying sub-processes in continuous ring die pelletizing through die temperature control. Fuel Process. Technol., 2014; 123: 122-126.

[11] Larsson, S.H., Rudolfsson, M., Nordwaeger, M., Olofsson, I., Samuelsson, R. Effects of moisture content, torrefaction temperature, and die temperature in pilot scale pelletizing of torrefied Norway spruce. Appl. Energ., 2013; 102: 827-832.

[12] Rudolfsson, M., Stelte, W., Lestander, T.A. Process optimization of combined biomass torrefaction and pelletization for fuel pellet production - A parametric study. Appl. Energ., 2015; 140: 378-384.

[13] Van der Stelt, M.J.C., Gerhauser, H., Kiel, J.H.A., Ptasinski, K.J. Biomass upgrading by torrefaction for the production of biofuels: A review. Biomass Bioenerg., 2011; 35: 3748-3762.

[14] Dai J., Sokhansanj S., Grace J.R., Bi X., Lim C.J., Melin S. Overview and some issues related to co-firing biomass and coal. Can. J. Chem. Eng.. 2008; 86: 367-86.

[15] Cummer K.R., Brown R.C. Ancillary equipment for biomass gasification. Biomass Bioenerg.. 2002; 23: 113-28.

[16] Falk, J., Berry, R.J., Broström, M., Larsson, S.H. Mass flow and variability in screw feeding of biomass powders - Relations to particle and bulk properties. Powder Technol., 2015; 276: 80-88. 
[17] Guo, Z., Chen, X., Liu, H., Chen, H. Gravity discharge characteristics of biomass-coal blends in a hopper. Fuel, 2014; 125: 137-143.

[18] Guo, Z., Chen, X., Xu, Y., Liu, H. Study of flow characteristics of biomass and biomass-coal blends. Fuel, 2015; 141: 207-213.

[19] Lestander T.A., Johnsson B., Grothage, M. NIR techniques create added values for the pellet and biofuel industry. Bioresource Technol. 2009; 100: 1589-1594.

[20] Lestander T.A., Finell M., Samuelsson R., Arshadi M., Thyrel, M. Industrial scale biofuel pellet production from blends of unbarked softwood and hardwood stems - the effects of raw material composition and moisture content on pellet quality. Fuel Process. Technol. 2012; 95: 73-77.

[21] Lestander, T.A., Rudolfsson, M., Pommer, L., Nordin, A. NIR provides excellent predictions of properties of biocoal from torrefaction and pyrolysis of biomass. Green Chem., 2014; 16: 4906-4913.

[22] Fasina O.O. Flow and physical properties of switchgrass, peanut hull, and poultry litter. Trans. ASABE 2006; 49: 721-728.

[23] Miccio F., Landi A., Barletta D., Poletto M. Preliminary assessment of a simple method for evaluating the flow properties of solid recovered fuels. Particul. Sci. Technol. 2009; 27: 139-151.

[24] Ramírez A., Moya M., Ayuga F. Determination of the mechanical properties of powdered agricultural products and sugar. Part. Part. Syst. Charact. 2009; 26: 220-230.

[25] Wu M.R., Schott D.L., Lodewijks G. Physical properties of solid biomass, Biomass Bioenerg. 2011; 35: 2093-2105.

[26] Chevanan N., Womac A.R., Bitra V.S.P., Yoder D.C., Sokhansanj S. Flowability parameters for chopped switchgrass, wheat straw and corn stover. Powder Technol. 2009; 193: 79-86.

[27] Adapa P., Tabil L., Schoenau G. Physical and frictional properties of non-treated and steam exploded barley, canola, oat and wheat straw grinds. Powder Technol. 2010; 201: 230-241. 
[28] Larsson S. Kinematic wall friction properties of reed canary grass powder at high and low normal stresses. Powder Technol. 2010; 198: 108-113.

[29] Owonikoko A., Berry R.J., Bradley M.S.A. The difficulties of handling biomass and waste: Characterisation of extreme shape materials. Bulk Solids Handling 2011; 31 (7-8): 366-371.

[30] Jenike A.W. Storage and flow of solids. University of Utah. Utah Engineering. Experiment Station, Bulletin 123, 1964.

[31] Mattsson J.E. Tendency to bridge over openings for chopped phalaris and straw of triticum mixed in different proportions with wood chips. Biomass Bioenerg. 1997; 12: 199-210.

[32] Mattsson J.E., Kofman P.D. Method and apparatus for measuring the tendency of solid biofuels to bridge over openings, Biomass Bioenerg. 2002; 22: 179-185.

[33] Mattsson J.E., Kofman P.D. Influence of particle size and moisture content on tendency to bridge in biofuels made from willow shoots. Biomass Bioenerg. 2003; 24: 429-435.

[34] Jensen P.D., Mattsson J.E., Kofman P.D., Klausner A. Tendency of wood fuels from whole trees, logging residues and roundwood to bridge over openings. Biomass Bioenerg. 2004; 26: 107-113.

[35] Cannavacciuolo A., Barletta D., Donsì G., Ferrari G., Poletto M. Arch-free flow in aerated silo discharge of cohesive powders. Powder Technol. 2009; 191: 272-270.

[36] Paulrud S., Mattsson J.E., Nilsson C. Particle and handling characteristics of wood fuel powder: effects of different mills. Fuel Process. Technol. 2002; 76: 23-39.

[37] Hinterreiter S., Hartmann H., Turowski P. Method for determining bridging properties of biomass fuelsexperimental and model approach. Biomass Conv. Bioref. 2012; 2: 109-121.

[38] Gil M., Arauzo I., Teruel E., Bartolomé C. Milling and handling Cynara Cardunculus L. for use as solid biofuel: Experimental tests. Biomass \& Bioenerg. 2012; 41: 145-156. 
[39] Miccio F., Silvestri N., Barletta D., Poletto M. Characterization of woody biomass flowability. Chem. Eng. Trans. 2011; 24: 643-648.

[40] Miccio F., Barletta D., Poletto M. Flow properties and arching behavior of biomass particulate solids. Powder Technol. 2013; 235: 312-321.

[41] Barletta D., Poletto M. An assessment on silo design procedures for granular solid biomass. Chem. Eng. Trans. 2013; 32: 2209-2214.

[42] Saleh, K., Moufarej Abou Jaoude, M.-T., Morgeneyer, M., Lefrancois, E., Le Bihan, O., Bouillard, J. Dust generation from powders: A characterization test based on stirred fluidization. Powder Technol., 2014, 255, 141-148.

[43] Beck, H., Glienke, N., Möhlmann, C. Combustion and explosion characteristics of dusts, BIA-Report 13/97: Hauptverband der gewerblichen Berufsgenossenschaften (HVBG); Sankt Augustin 1997.

[44] Eckhoff R., Dust Explosions in the Process Industries, 3rd Edition: Gulf Professional Publishing; 2003.

[45] CEN/TS 15149-1:2006. Solid biofuels - Methods for the determination of particle size distribution - Part 1: Oscillating screen method using sieve apertures of $3.15 \mathrm{~mm}$ and above.

[46] CEN/TS 15149-2:2006. Solid biofuels - Methods for the determination of particle size distribution - Part 2: Vibrating screen method using sieve apertures of $3.15 \mathrm{~mm}$ and below.

[47] Gil, M., Teruel, E., Arauzo, I. Analysis of standard sieving method for milled biomass through image processing. Effects of particle shape and size for poplar and corn stover. Fuel, 2014; 116, 328-340.

[48] Schulze D. Development and application of a novel ring shear tester. Aufbereitungstechnik 1994; 35 : $524-535$.

[49] ASTM. Standard shear test method for bulk solids using the Schulze ring shear tester. Ref. No. D677308. 2008. 
[50] Berry R.J., Bradley M.S.A., McGregor R.J. Development and commercialisation of a new Powder Flow Tester for powder formulation development, quality control and equipment design; Proceedings of 6th World Congress on Powder Technology; Nuremberg, Germany; April 2010.

[51] Berry R.J., Bradley M.S.A. Investigation of the effect of test procedure factors on the failure loci and derived failure functions obtained from annular shear cells. Powder Technol. 2007; 174: 60-63.

[52] Ramírez Á., Moya M., Ayuga F. Determination of the Mechanical Properties of Powdered Agricultural Products and Sugar. Part. Part. Syst. Charact. 2010; 26: 220-230.

[53] Eurocode 1. Basis of design and actions on structures. Part 4: Actions on Structures. Silos and Tanks. Brussels, European Committee on Standardization, 2006.

[54] Jenike A.W. Gravity flow of bulk solids. University of Utah, USA. Utah Engineering. Experiment Station, Bulletin 108; 1961.

[55] Jenike A.W., Leser T. A flow-no flow criterion in the gravity flow of powders in converging channels. Proc. $4^{\text {th }}$ Int. Congress on Rheology, 1963; 125-140.

[56] Arnold P.C., McLean A.G. Improved analytical flow factor for mass-flow hoppers. Powder Technol. 1976; 15: $279-281$.

[57] Arnold P.C., McLean A.G., Roberts A.W. Bulk solids: Storage Flow and Handling. TUNRA, Australia; 1980.

[58] Abassi , T., Abassi, S.A. Dust explosions-Cases, causes, consequences, and control, J Hazard Mater. 2007; 140: $7-44$. 


\section{Table captions}

Table 1. Tests performed by the Bio4Flow research partners.

Table 2. Particle size measurement techniques.

Table 3. Main outlet design values

Table 4. Explosion parameters of the analysed samples.

Table 5. Summary of applied characterisation methods. An X indicates the possibility to use the method on the line with the material in the column. For size measurements, L, W and T indicate the possibility to measure the particle length, width and thickness.

\section{Figure captions}

Figure 1. Biomass materials used in the experiments: a) Scots pine (Pinus sylvestris) wood chips; b) Scots pine (Pinus sylvestris) wood powder; c) reed canary grass (Phalaris arundinacea) straw chops.

Figure 2. Sketch of the Casagrande direct shear tester prepared for: a) internal friction and b) wall friction.

Figure 3. Experimental plane silo with variable shape a) sketch; b) full size view; c) material leveling before experiments; d) and e) silo opening; f) stable arch; g) material collected in the discharge basin.

Figure 4. Particle size distributions in cumulative weight fraction for particle length ( $a$ and $b$ ), particle width ( $c$ and d), and particle thickness (e and f), of wood chips (a, c and e) and reed canary grass (b, $d$ and f) measured with various techniques:,$- 2 \mathrm{D}$ image analysis; $\cdots \cdots . .$, 3D ScanChip analysis; - - - , single particle caliper measurements; $-\cdot-\cdot-$, sieving.

Figure 5. Particle shape distributions for: a) the elongation in cumulative area $\%$ and b) equivalent area diameter for different elongation classes. - and $\boldsymbol{\bullet}$, wood chips; $-\longrightarrow$, and $\mathbf{\Lambda}$, reed canary grass.

Figure 6. Particle size distributions obtained by sieving for wood powder. 
Figure 7. Photograph of the large annular shear cell showing the formation of voids at the front of the lid pockets for the wood chips

Figure 8. Torsional and axial load traces from the PFT for a) wood powder and b) sand.

Figure 9. Bulk flow properties measured for wood chips using a range of shear testers.

Figure 10. Bulk flow properties measured for reed canary grass using a range of shear testers.

Figure 11. Bulk flow properties measured for wood powder using a range of shear testers.

Figure 12. Tensile Strength Functions measured for the three biomass materials in The Wolfson Centre Tensile Tester.

Figure 13. Wall friction functions measured in a range of different shear testers for a) reed canary grass RCG, b) wood powder and c) wood chips.

Figure 14. Critical hopper outlet size for arching: a) wood chips; b) reed canary grass; c) wood powder; ๑, experiments; $\bigcirc$, theory with RST data; $\square$, theory with PFT data; $\diamond$ theory with LAST data; $\nabla$, theory with tensile test data. 
Table 1. Tests performed by the Bio4Flow research partners.

\begin{tabular}{|c|c|c|c|c|}
\hline Characterisation method & SLU BTC & UG Wolf & US PTG & $\begin{array}{c}\text { UPM } \\
\text { BIPREE }\end{array}$ \\
\hline \multicolumn{5}{|l|}{ Particle size distribution } \\
\hline Sieve analysis & $x$ & & & \\
\hline 2D image analysis & & & $x$ & \\
\hline 3D image analysis - Scanchip & $x$ & & & \\
\hline Caliper & & $x$ & & \\
\hline \multicolumn{5}{|l|}{ Powder flow properties } \\
\hline Shear tests powder flow tester & & $x$ & $x$ & \\
\hline Shear tests - Schulze shear tester & $x$ & & & \\
\hline Shear tests - large annular shear cell & & $x$ & & \\
\hline Tensile tests & & $x$ & & \\
\hline Wall friction-powder flow tester & & $x$ & $x$ & \\
\hline Wall friction-large Jenike shear cell & & $x$ & & \\
\hline Wall friction-Casagrande shear box & & & & $x$ \\
\hline Arching test in a model silo & & & $x$ & \\
\hline \multicolumn{5}{|l|}{ Safety properties } \\
\hline Explosion test & & & & $\mathrm{x}$ \\
\hline
\end{tabular}


Table 2. Particle size measurement techniques.

\begin{tabular}{|l|l|l|l|}
\hline Technique & Method(s) & Materials analyzed & Sample size \\
\hline Caliper & Manual measurements & Wood chips & 320 pieces \\
\hline 2D image analysis & Image analysis software & Wood chips & 100 pieces \\
\hline 3D image analysis & ScanChip & RCG & 8800 pieces \\
\hline Sieving & EN 15149-1:2010 & Wood chips & 16000 pieces \\
& EN 15149-2:2010 & RCG & 12000 pieces \\
\hline & & Wood powder & $50 \mathrm{~g}$ \\
\hline
\end{tabular}


Table 3. Main silo outlet design values

\begin{tabular}{|c|c|c|c|c|c|}
\hline Material & $\begin{array}{c}\alpha \\
{\left[{ }^{\circ}\right]}\end{array}$ & $\begin{array}{l}H \\
{[-]}\end{array}$ & $\begin{array}{l}f f \\
{[-]}\end{array}$ & $\begin{array}{c}f_{\mathrm{c}}{ }^{*} \text { or } \sigma_{\mathrm{t}}{ }^{*} \\
{[\mathrm{~Pa}]}\end{array}$ & $\begin{array}{c}D_{c} \text { (design) } \\
{[\mathrm{m}]}\end{array}$ \\
\hline \multirow{8}{*}{$\begin{array}{l}\text { Wood chips } \\
\text { LAST data }\end{array}$} & 40 & 1.20 & 1.50 & 528 & 0.43 \\
\hline & 38 & 1.19 & 1.48 & 526 & 0.43 \\
\hline & 35 & 1.18 & 1.45 & 523 & 0.42 \\
\hline & 33 & 1.17 & 1.40 & 519 & 0.41 \\
\hline & 30 & 1.15 & 1.35 & 515 & 0.40 \\
\hline & 28 & 1.14 & 1.32 & 512 & 0.40 \\
\hline & 25 & 1.13 & 1.28 & 509 & 0.39 \\
\hline & 20 & 1.10 & 1.24 & 506 & 0.38 \\
\hline \multirow[t]{7}{*}{\begin{tabular}{|l|} 
Wood chips \\
Tensile test data \\
\end{tabular}} & 40 & & 1.50 & 96 & 0.066 \\
\hline & 38 & - & 1.48 & 96 & 0.065 \\
\hline & 35 & - & 1.45 & 96 & 0.065 \\
\hline & 33 & - & 1.40 & 95 & 0.065 \\
\hline & 30 & - & 1.35 & 94 & 0.064 \\
\hline & 28 & - & 1.32 & 94 & 0.064 \\
\hline & 25 & - & 1.28 & 94 & 0.064 \\
\hline \multirow{5}{*}{$\begin{array}{l}\text { Reed canary grass } \\
\text { RST data } \\
\end{array}$} & 40 & 1.20 & 1.38 & 126 & 0.171 \\
\hline & 35 & 1.18 & 1.32 & 124 & 0.165 \\
\hline & 30 & 1.15 & 1.29 & 123 & 0.160 \\
\hline & 25 & 1.13 & 1.28 & 123 & 0.156 \\
\hline & 20 & 1.10 & 1.29 & 123 & 0.153 \\
\hline \multirow[t]{5}{*}{$\begin{array}{l}\text { Reed canary grass } \\
\text { PFT data }\end{array}$} & 40 & 1.20 & 1.59 & 255 & 0.35 \\
\hline & 35 & 1.18 & 1.57 & 254 & 0.34 \\
\hline & 30 & 1.15 & 1.58 & 254 & 0.33 \\
\hline & 25 & 1.13 & 1.61 & 257 & 0.33 \\
\hline & 20 & 1.10 & 1.65 & 263 & 0.33 \\
\hline \multirow[t]{5}{*}{$\begin{array}{l}\text { Reed canary grass } \\
\text { LAST data }\end{array}$} & 40 & 1.20 & 1.47 & 337 & 0.46 \\
\hline & 35 & 1.18 & 1.36 & 334 & 0.44 \\
\hline & 30 & 1.15 & 1.29 & 332 & 0.43 \\
\hline & 25 & 1.13 & 1.25 & 331 & 0.42 \\
\hline & 20 & 1.10 & 1.23 & 331 & 0.41 \\
\hline \multirow[t]{3}{*}{$\begin{array}{l}\text { Reed canary grass } \\
\text { Tensile test data }\end{array}$} & 40 & - & 1.47 & 52 & 0.059 \\
\hline & 35 & - & 1.36 & 65 & 0.074 \\
\hline & 30 & - & 1.29 & 60 & 0.068 \\
\hline
\end{tabular}




\begin{tabular}{|c|c|c|c|c|c|}
\hline & 25 & - & 1.25 & 56 & 0.064 \\
\hline & 20 & - & 1.23 & 53 & 0.061 \\
\hline \multirow{8}{*}{$\begin{array}{l}\text { Wood powder } \\
\text { RST data }\end{array}$} & 38 & 1.19 & 1.23 & 285 & 0.15 \\
\hline & 35 & 1.18 & 1.21 & 285 & 0.15 \\
\hline & 33 & 1.17 & 1.21 & 284 & 0.14 \\
\hline & 30 & 1.15 & 1.21 & 284 & 0.14 \\
\hline & 28 & 1.14 & 1.22 & 285 & 0.14 \\
\hline & 25 & 1.13 & 1.23 & 286 & 0.14 \\
\hline & 23 & 1.12 & 1.25 & 287 & 0.14 \\
\hline & 20 & 1.10 & 1.28 & 289 & 0.14 \\
\hline \multirow{7}{*}{$\begin{array}{l}\text { Wood powder } \\
\text { PFT data }\end{array}$} & 38 & 1.19 & 1.30 & 519 & 0.27 \\
\hline & 35 & 1.18 & 1.28 & 516 & 0.26 \\
\hline & 33 & 1.17 & 1.27 & 514 & 0.26 \\
\hline & 30 & 1.15 & 1.27 & 514 & 0.26 \\
\hline & 28 & 1.14 & 1.27 & 514 & 0.25 \\
\hline & 25 & 1.13 & 1.29 & 516 & 0.25 \\
\hline & 23 & 1.12 & 1.30 & 518 & 0.25 \\
\hline \multirow[t]{7}{*}{$\begin{array}{l}\text { Wood powder } \\
\text { LAST data }\end{array}$} & 38 & - & 1.76 & 453 & 0.23 \\
\hline & 35 & - & 1.64 & 439 & 0.22 \\
\hline & 33 & - & 1.58 & 431 & 0.22 \\
\hline & 30 & - & 1.49 & 423 & 0.21 \\
\hline & 28 & - & 1.44 & 418 & 0.21 \\
\hline & 25 & - & 1.38 & 412 & 0.20 \\
\hline & 23 & - & 1.35 & 409 & 0.20 \\
\hline
\end{tabular}


Table 4. Explosion parameters.

\begin{tabular}{|l|l|l|l|l|l|}
\hline Dust sample & $\begin{array}{l}\text { Pmax } \\
(\text { bar.g) }\end{array}$ & $\begin{array}{l}\text { (dP/dt)max } \\
(\mathrm{bar} / \mathrm{s})\end{array}$ & Combustion duration $(\mathrm{ms})$ & $\begin{array}{l}\text { Kst } \\
(\text { bar.m/s) }\end{array}$ & Explosion class \\
\hline Scots pine & 7.4 & 553 & 41 & 150 & St1 \\
\hline Reed canary grass & 7.2 & 579 & 32 & 157 & St1 \\
\hline Lignite & $7.3-10$ & -- & -- & $32-176$ & St1 \\
\hline
\end{tabular}


Table 5. Summary of applied characterisation methods. $X$ indicates performed measurement. For size measurements, L, W and T indicate measurements of particle length, width and thickness, respectively.

\begin{tabular}{|c|c|c|c|}
\hline Characterisation method & wood chips & RCG & wood powder \\
\hline \multicolumn{4}{|l|}{ Particle size distribution } \\
\hline Sieve analysis & W & W & W \\
\hline 2D image analysis & LW & LW & \\
\hline 3D image analysis - Scanchip & LWT & LWT & \\
\hline Caliper & LWT & LWT & \\
\hline \multicolumn{4}{|l|}{ Powder flow properties } \\
\hline Shear tests - powder flow tester & & $x$ & $X$ \\
\hline Shear tests - Schulze shear tester & $X$ & $X$ & $X$ \\
\hline Shear tests - large annular shear cell & $x$ & $\mathrm{X}$ & $\mathrm{X}$ \\
\hline Shear tests - Casagrande & & $\mathrm{X}$ & $x$ \\
\hline Tensile tests & $\mathrm{X}$ & $\mathrm{X}$ & $\mathrm{X}$ \\
\hline Wall friction - powder flow tester & & $X$ & $X$ \\
\hline Wall friction - large Jenike shear cell & $x$ & $\mathrm{X}$ & $x$ \\
\hline Wall friction-Casagrande & $X$ & $x$ & $x$ \\
\hline Arching test in a model silo & $\mathrm{X}$ & $X$ & $x$ \\
\hline \multicolumn{4}{|l|}{ Safety properties } \\
\hline Explosion test & & $X$ & $X$ \\
\hline
\end{tabular}



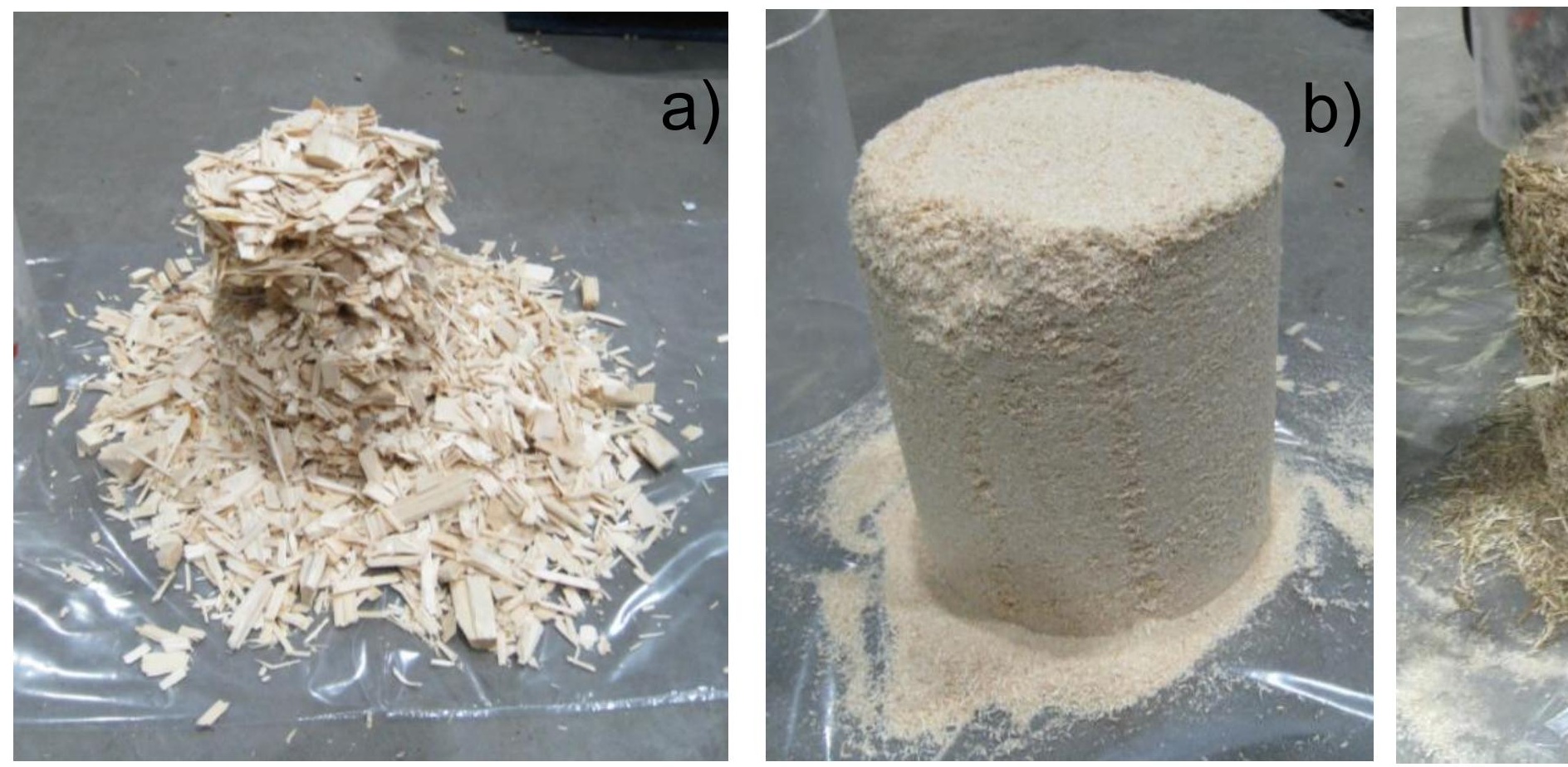

Figure 1. Biomass materials used in the experiments: a) Scots pine (Pinus sy/vestris) wood chips; b) Scots pine (Pinus sylvestris) wood powder; c) reed canary grass (Phalaris arundinacea) straw chops. 


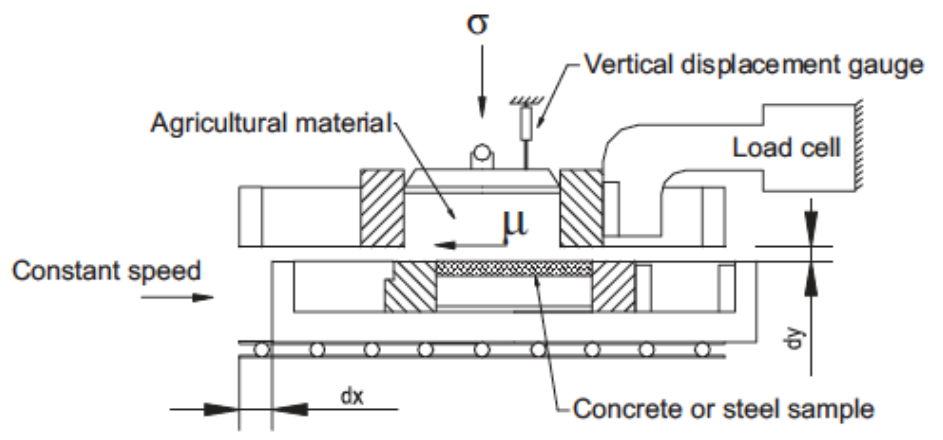

Figure 2. Sketch of the Casagrande direct shear tester prepared for wall friction test. 

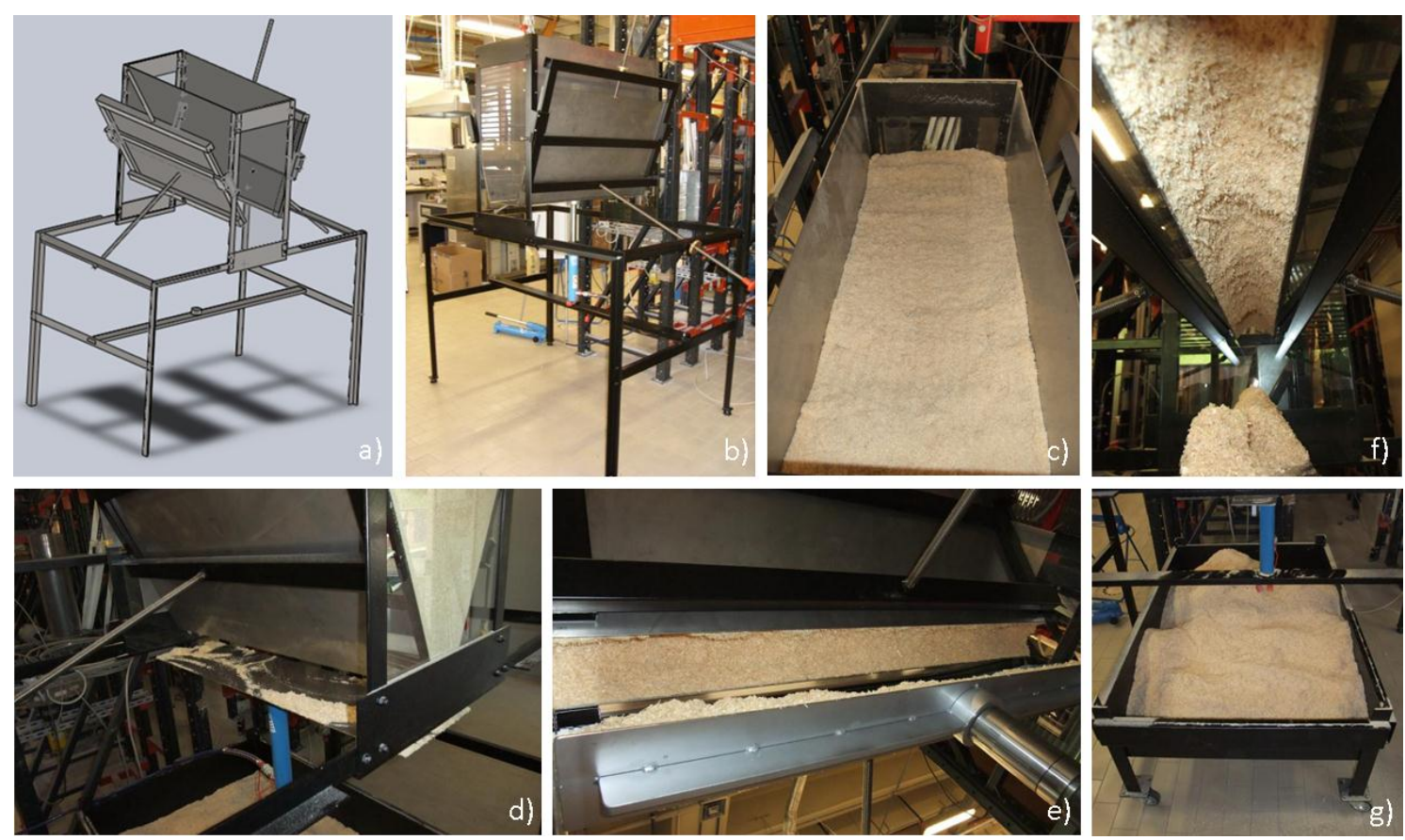

Figure 3. Experimental plane silo with variable shape a) sketch; b) full size view; c) material leveling before experiments; d) and e) silo opening; f) stable arch; g) material collected in the discharge basin. 

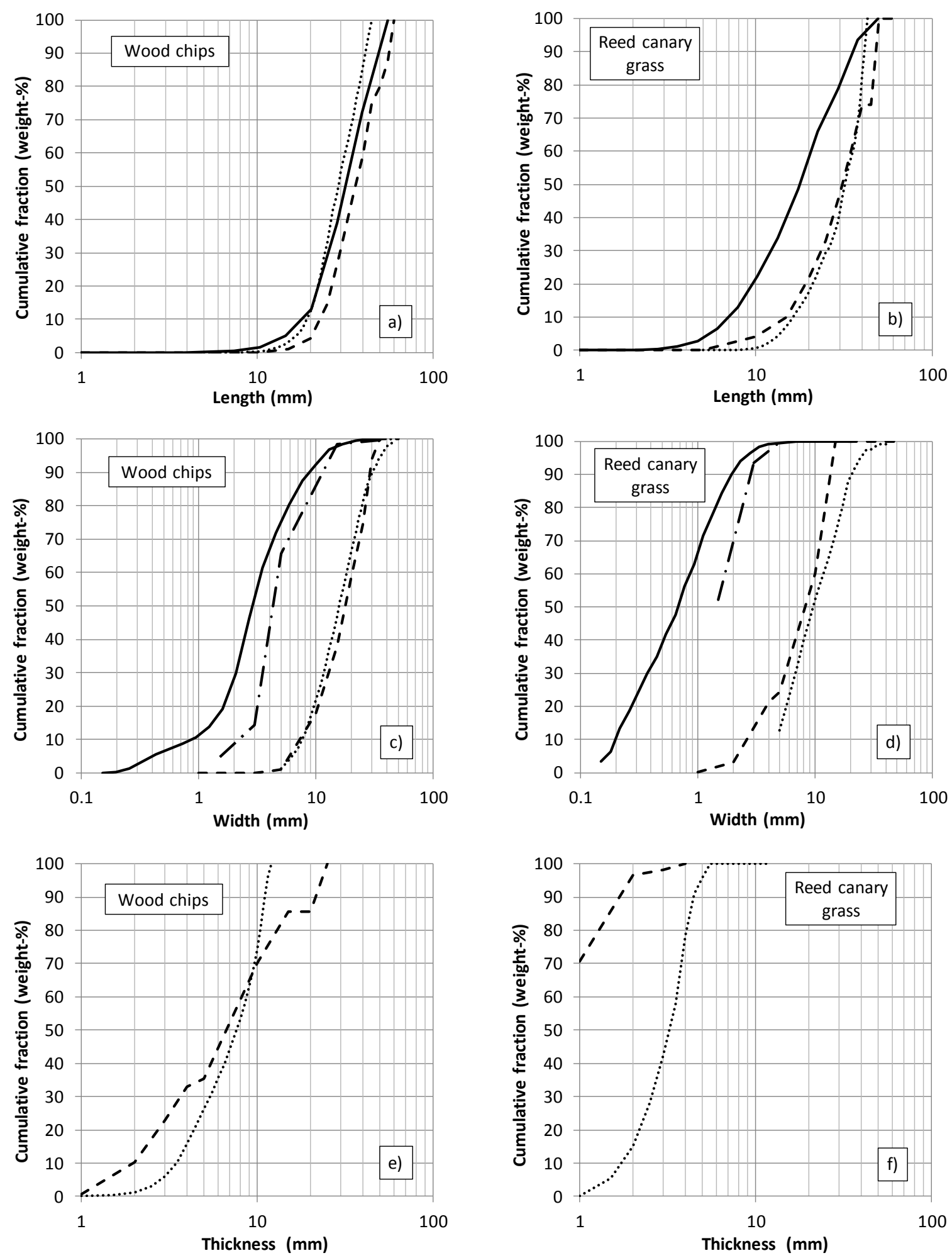

Figure 4. Particle size distributions in cumulative weight fraction for particle length ( $a$ and $b$ ), particle width (c and d), and particle thickness (e and f), of wood chips (a, c and e) and reed canary grass (b, d and f) measured with various techniques: - , 2D image analysis; $\cdots \cdots . ., 3 D$ ScanChip analysis; --- , single particle caliper measurements; $-\cdot-\cdot-$, sieving. 

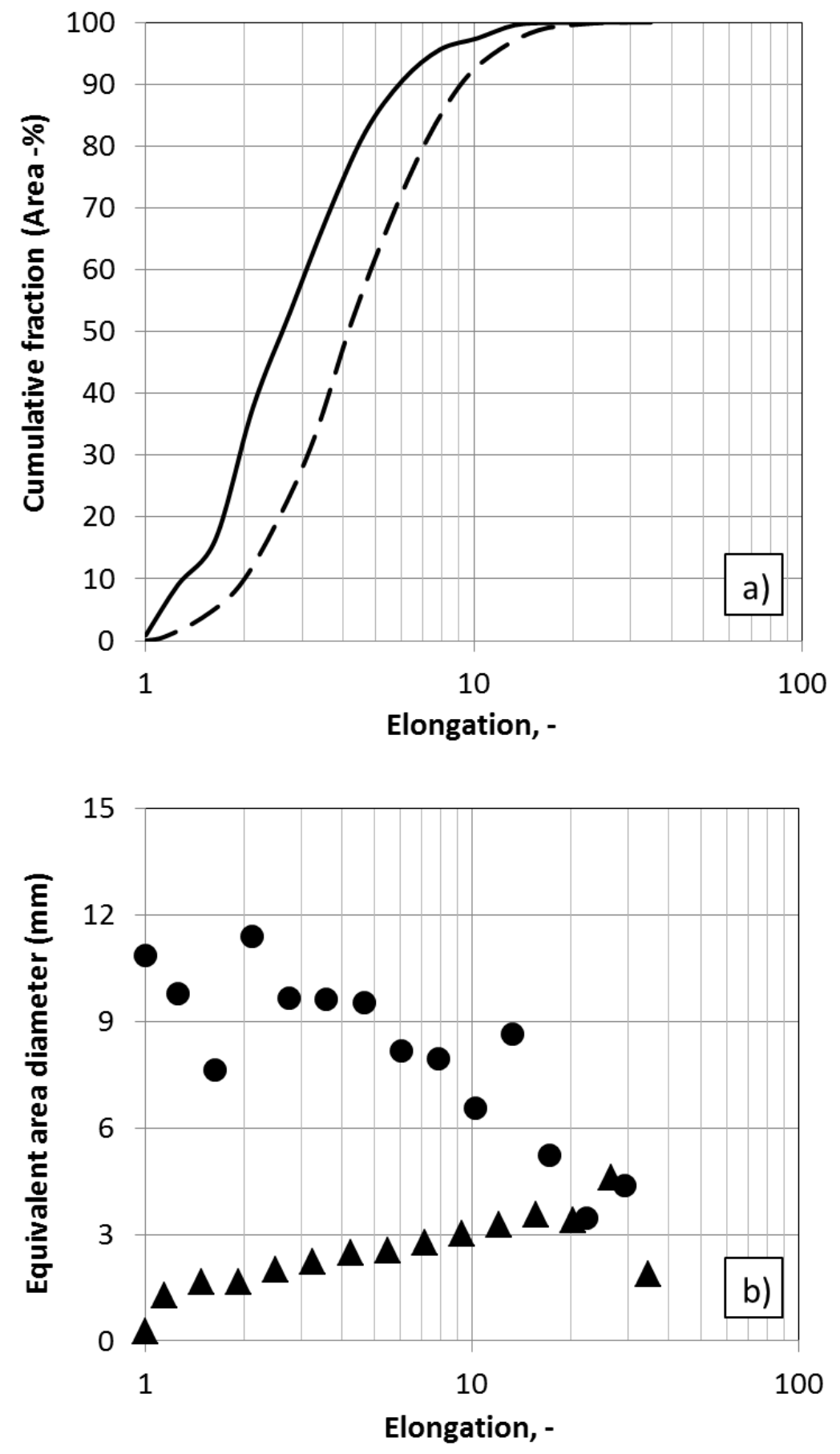

Figure 5. Particle shape distributions for: a) the elongation in cumulative area $\%$ and b) equivalent area diameter for different elongation classes. - and $\boldsymbol{\bullet}$, wood chips; $-\longrightarrow$, and $\mathbf{\Delta}$, reed canary grass. 


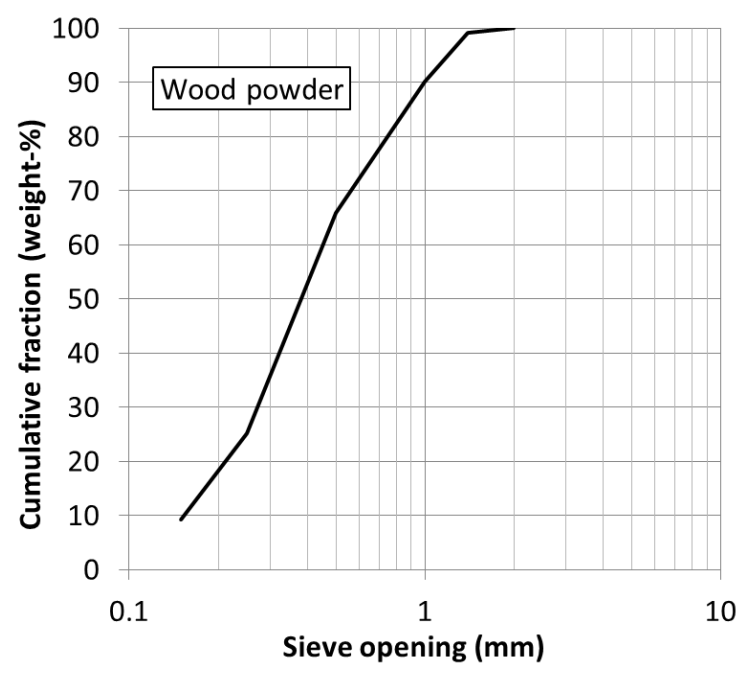

Figure 6. Particle size distribution for wood powder from sieve analysis. 


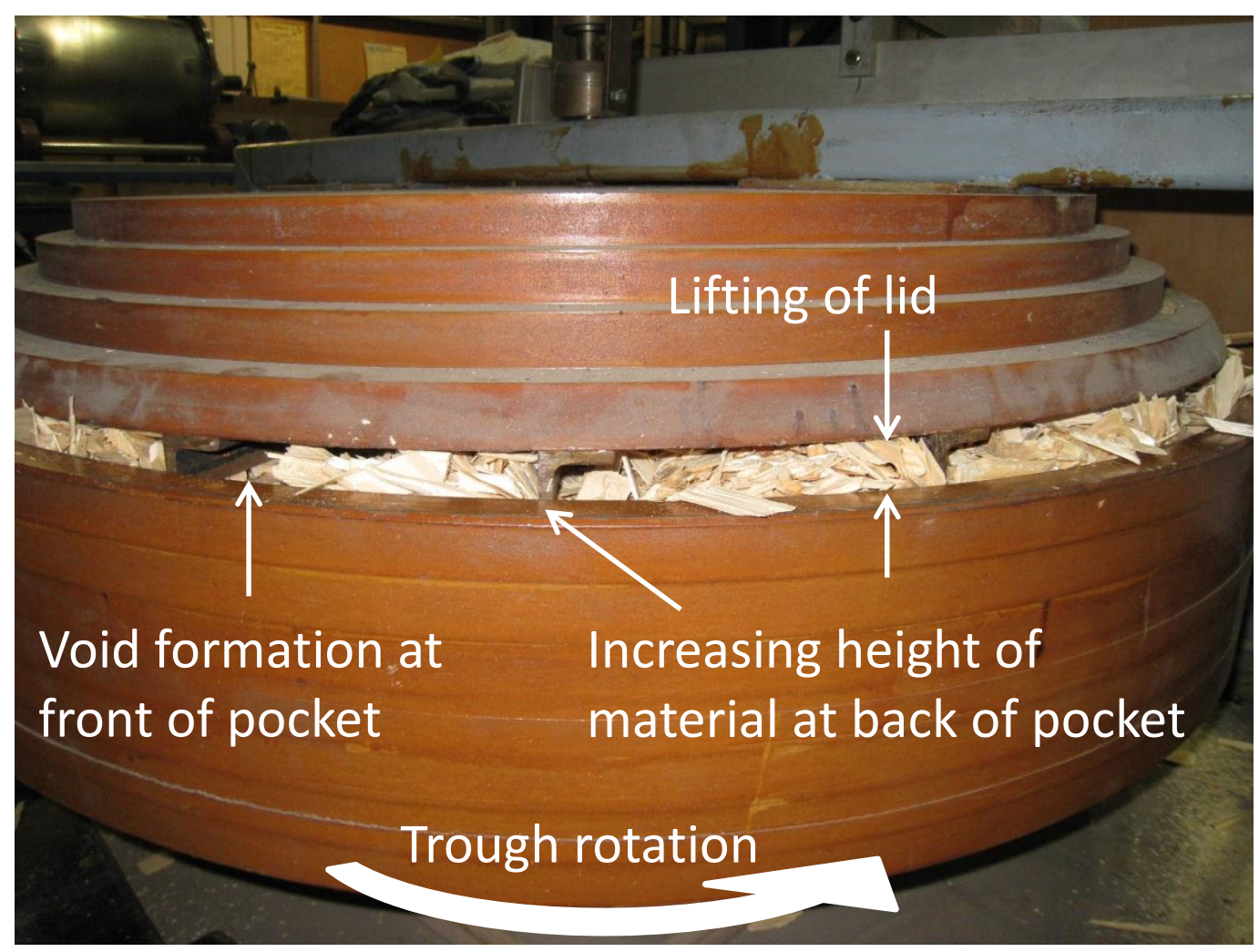

Figure 7. Photograph of the large annular shear cell showing the formation of voids at the front of the lid pockets when testing wood chips 


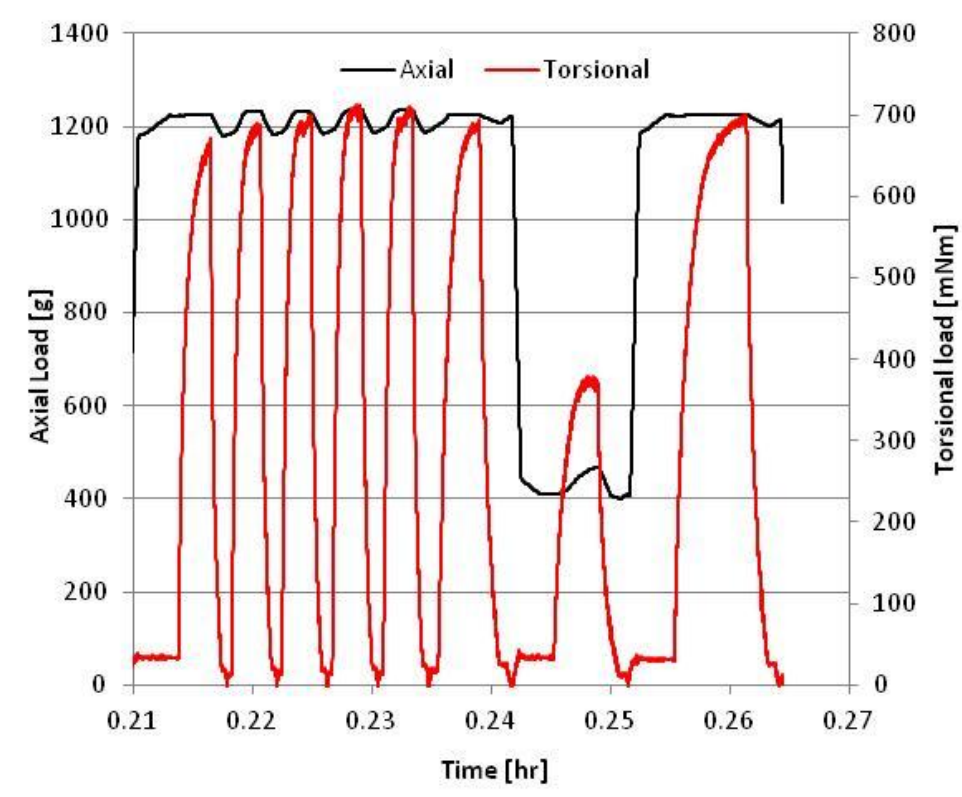

a)

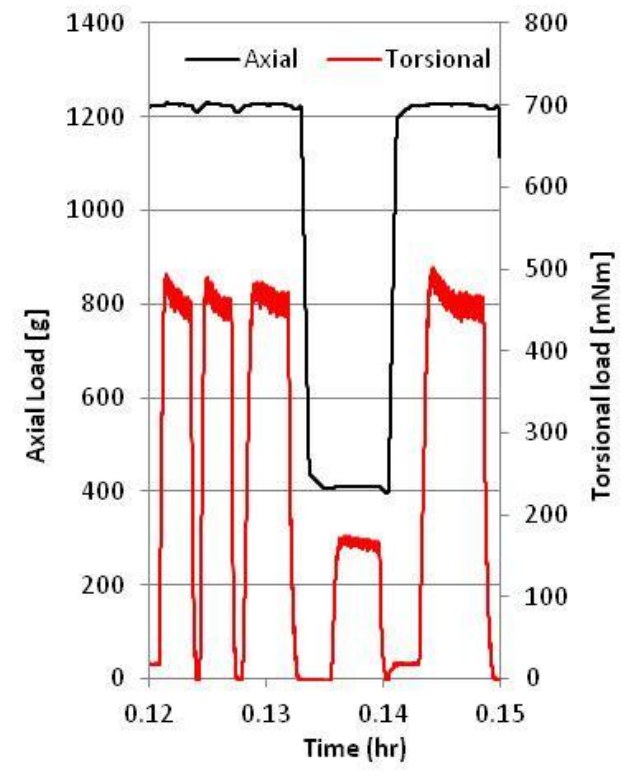

b)

Figure 8. Torsional and axial load traces from the Brookfield Powder Flow Tester (PFT) for a) wood powder and b) sand. 

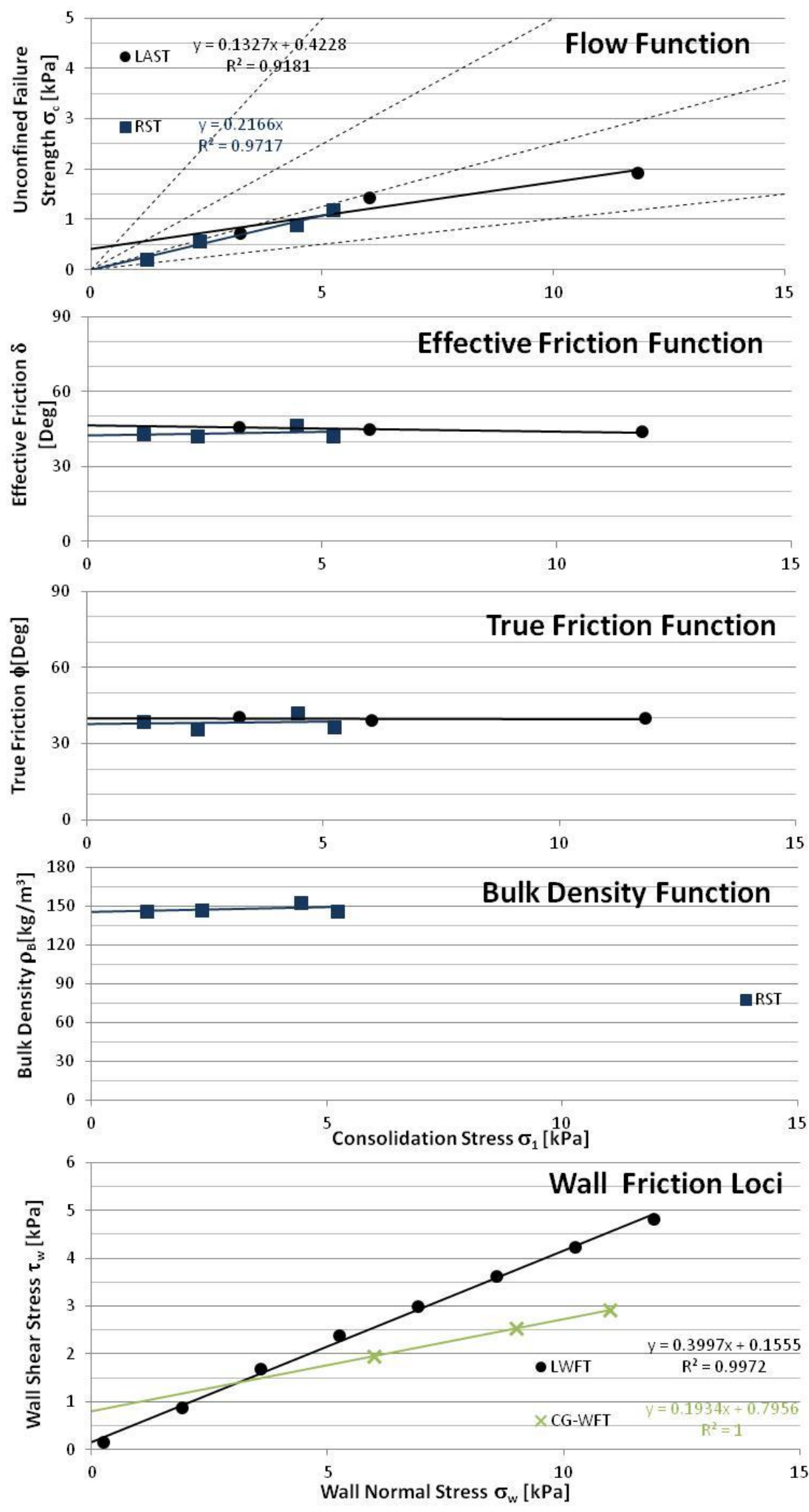

Figure 9. Bulk flow properties of wood chips using a range of shear testers. 

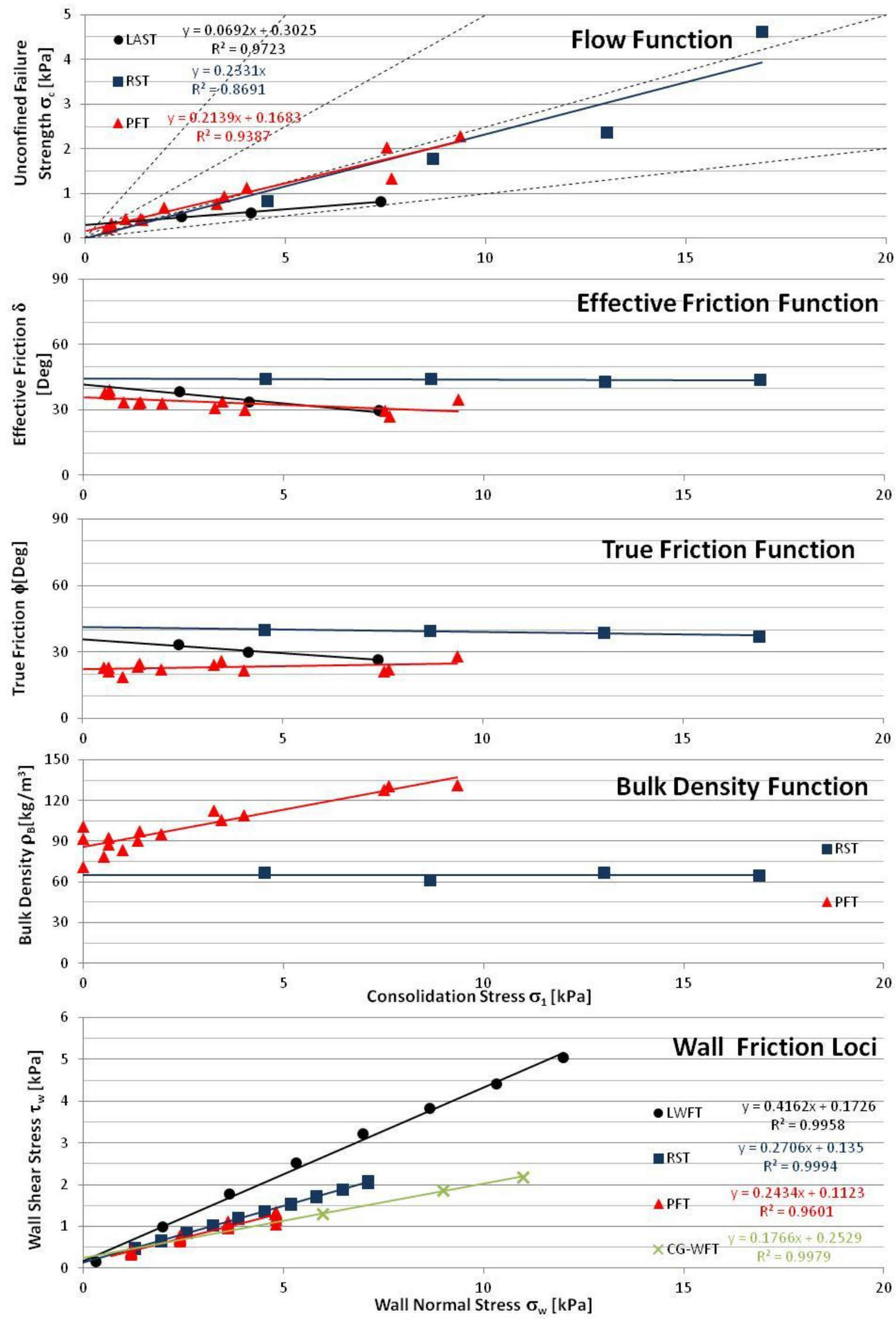

Figure 10. Bulk flow properties of reed canary grass (RCG) using a range of shear testers. 

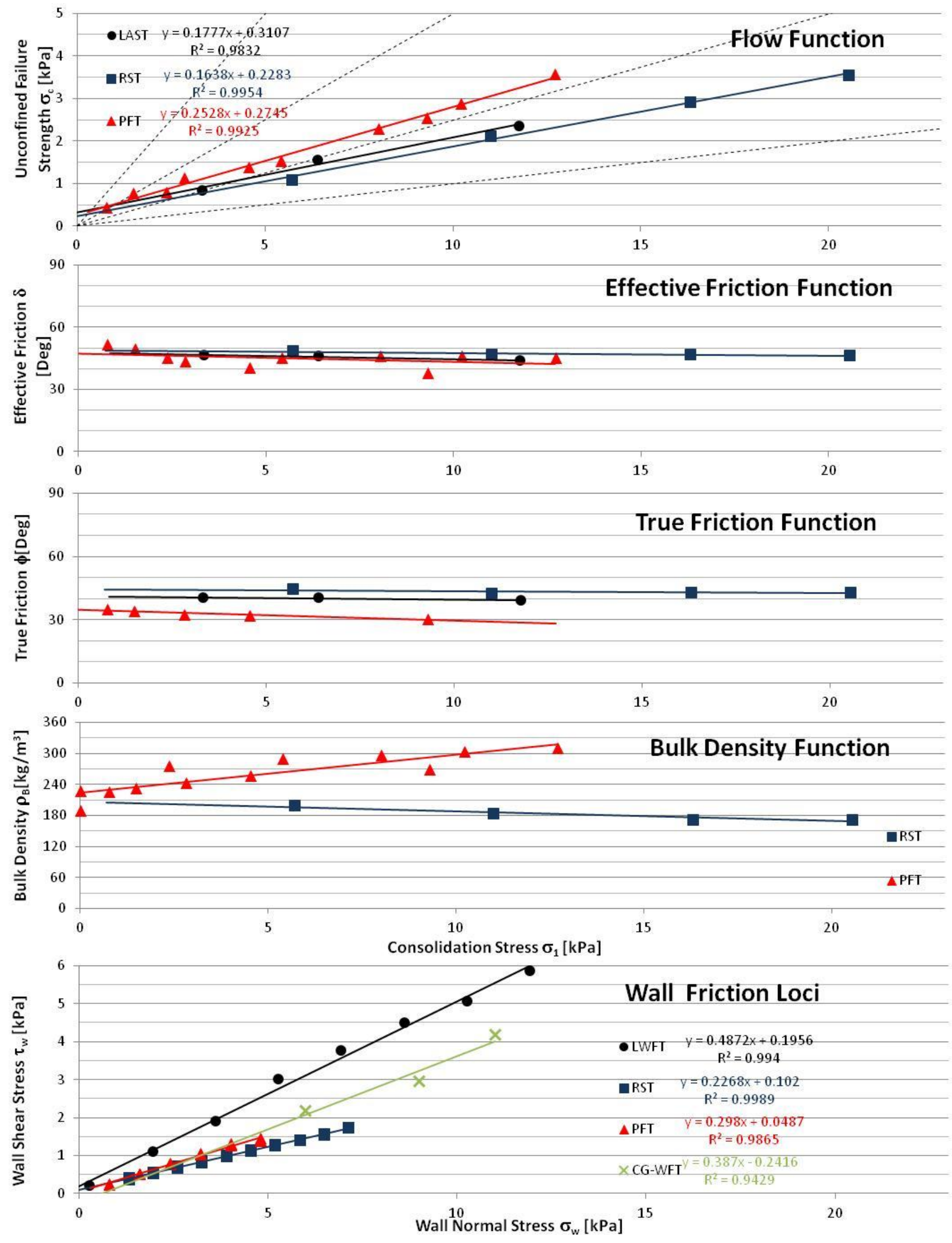

Figure 11. Bulk flow properties of wood powder using a range of shear testers. 


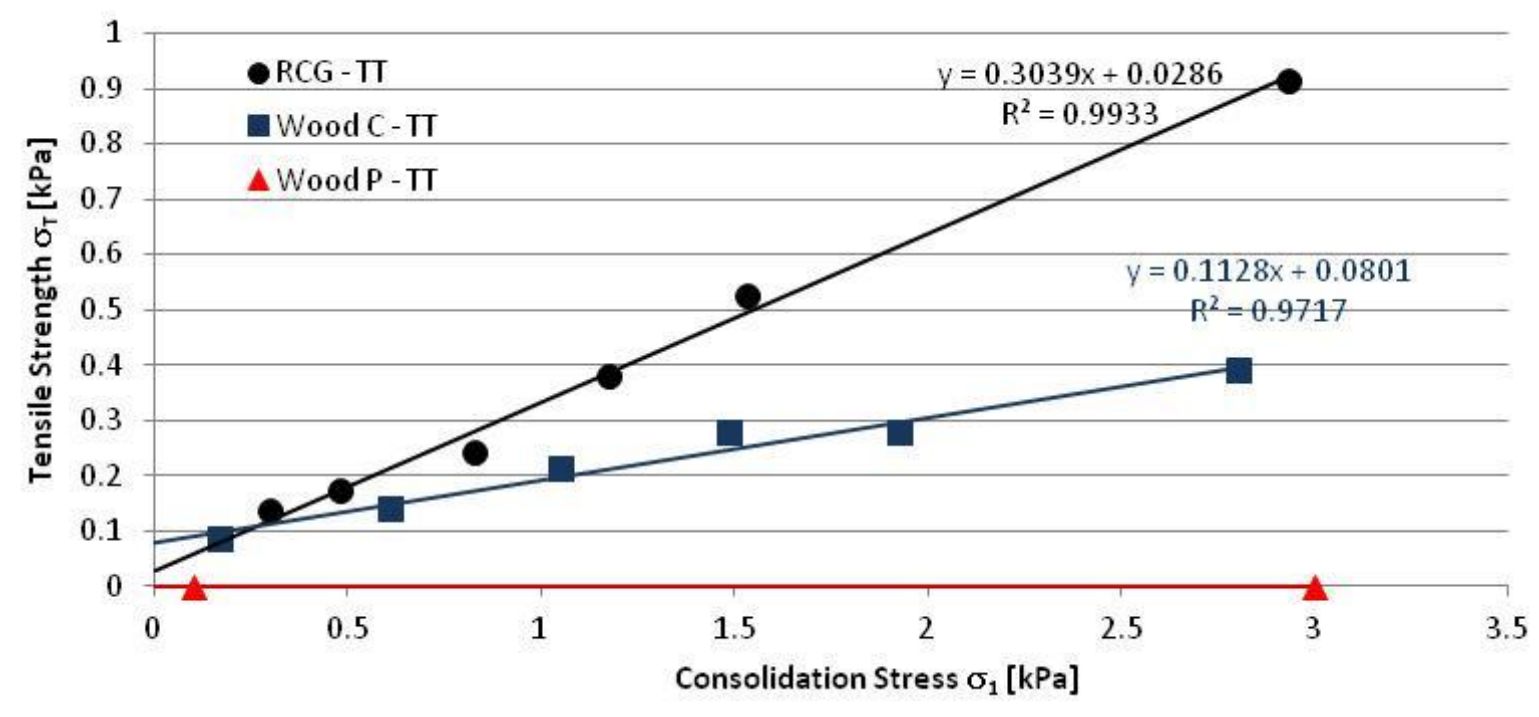

Figure 12. Tensile strength functions for the three biomass materials determined with the Wolfson Centre tensile tester. 


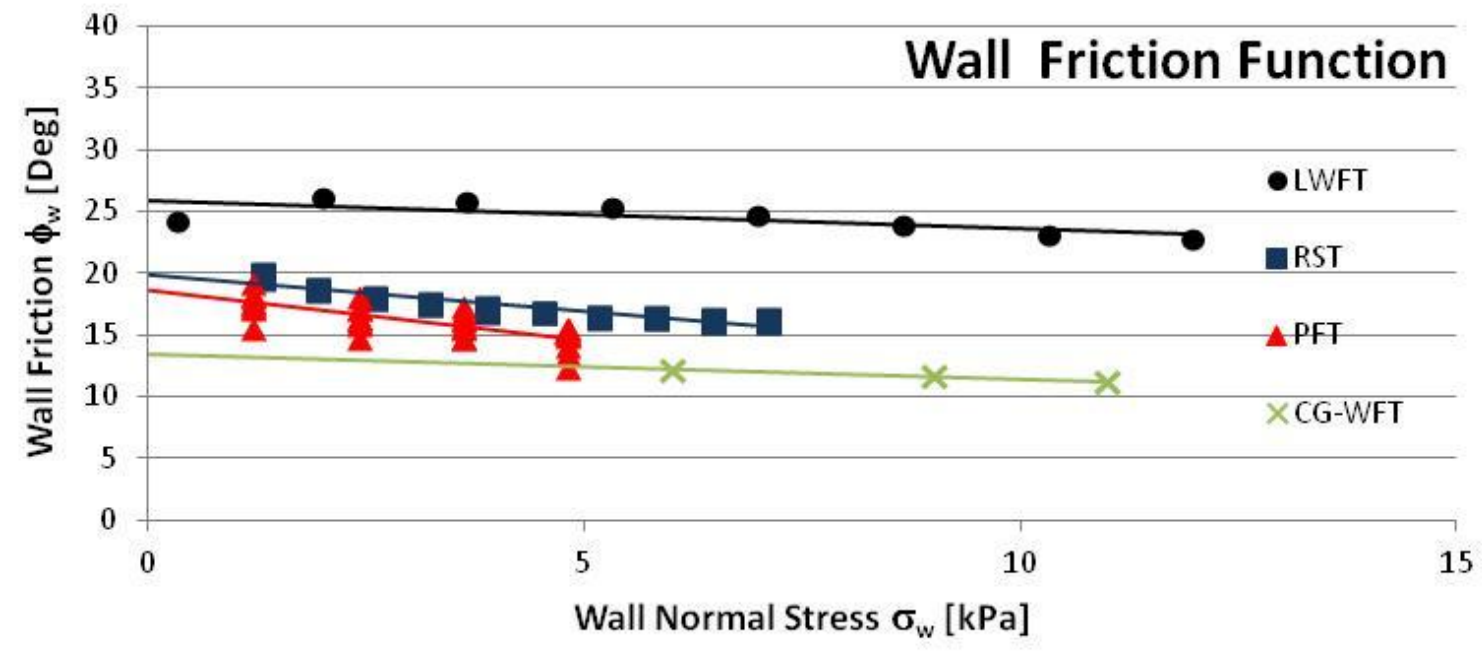

a)

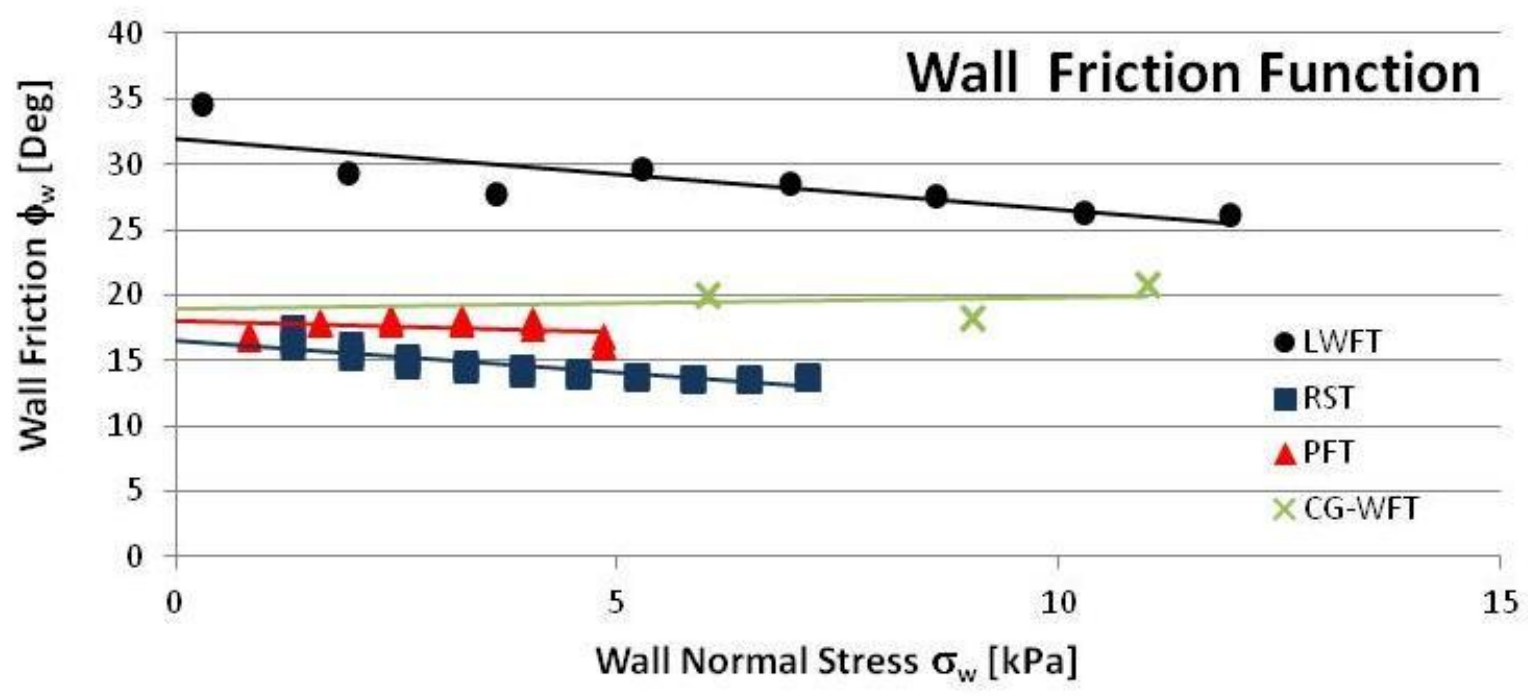

b)

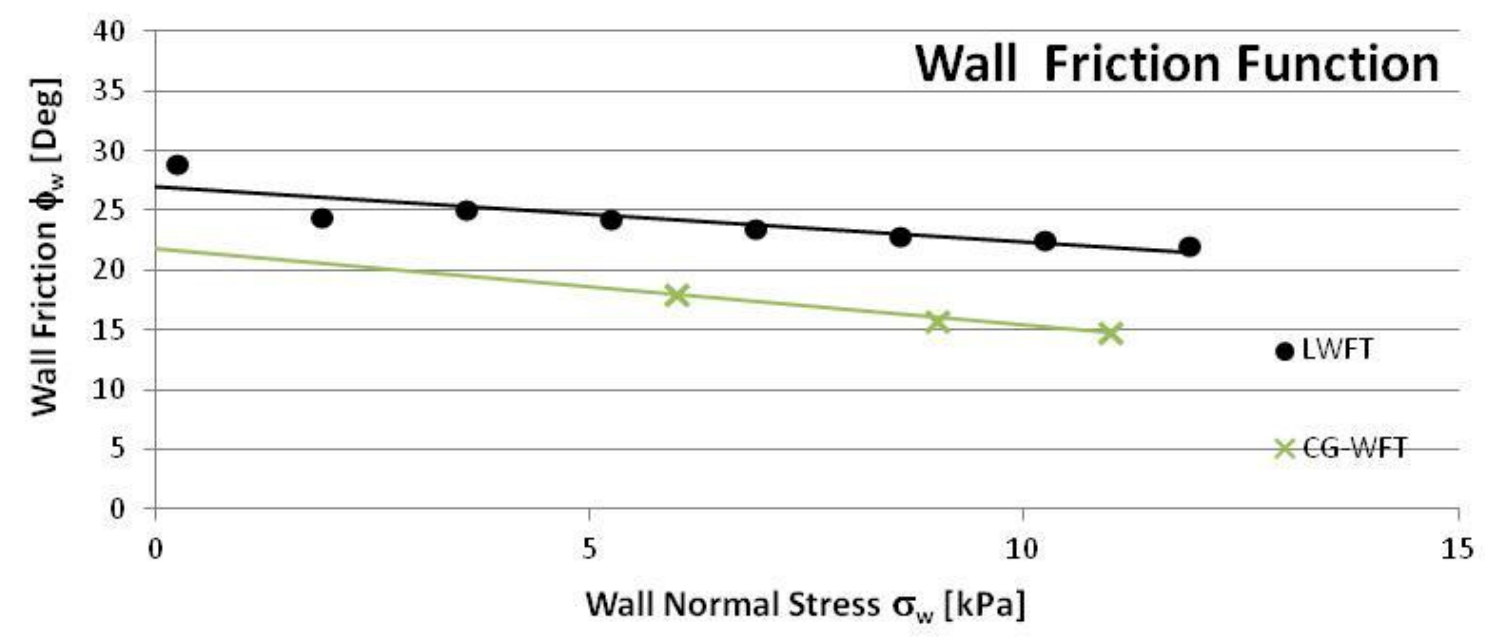

c)

Figure 13. Wall friction functions from a range of different shear testers for a) reed canary grass reed canary grass, b) wood powder and c) wood chips. 

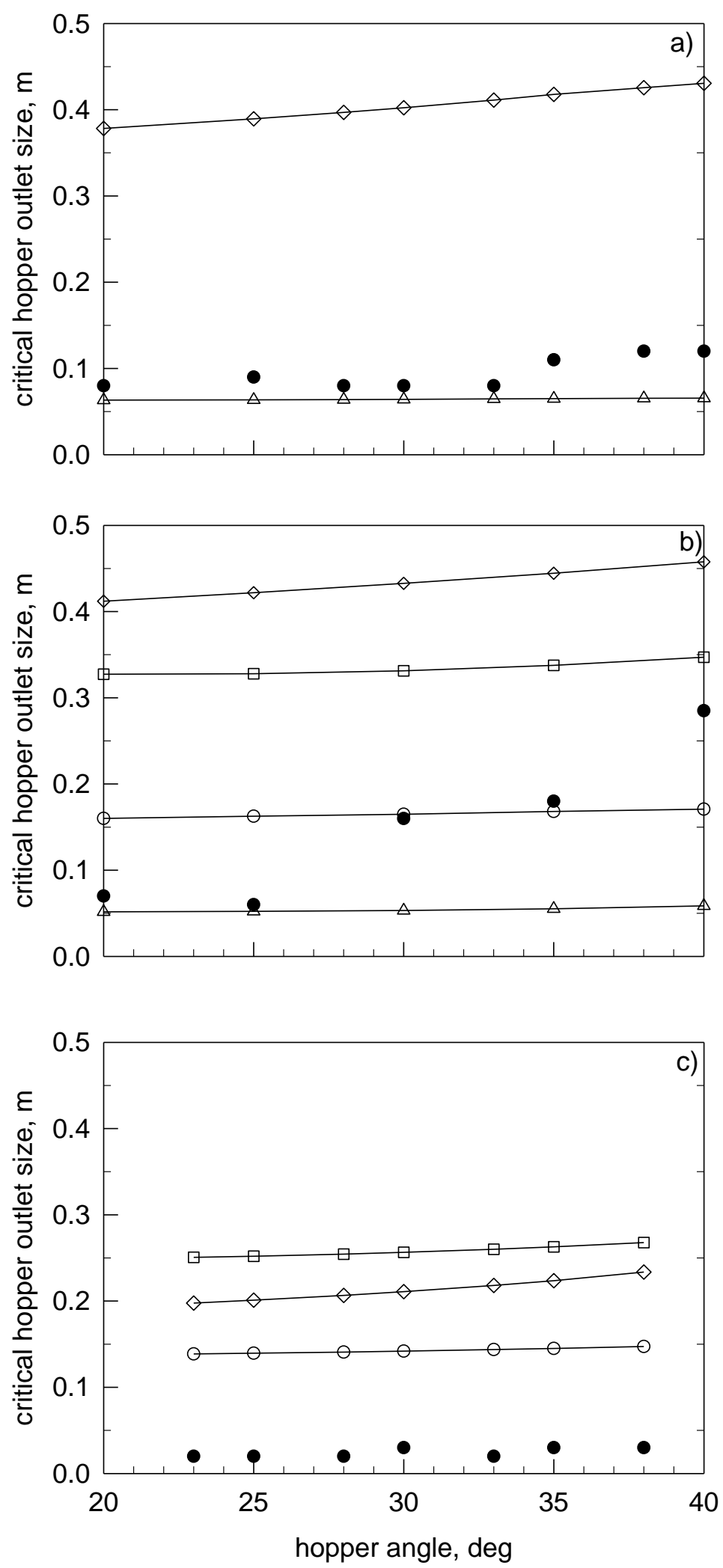

Figure 14. Critical hopper outlet size for arching: a) wood chips; b) reed canary grass; c) wood powder;

๑, experimental; $\bigcirc$ RST; $\square$ PFT; $\diamond$ LAST; and $\nabla$ tensile test based predictions. 

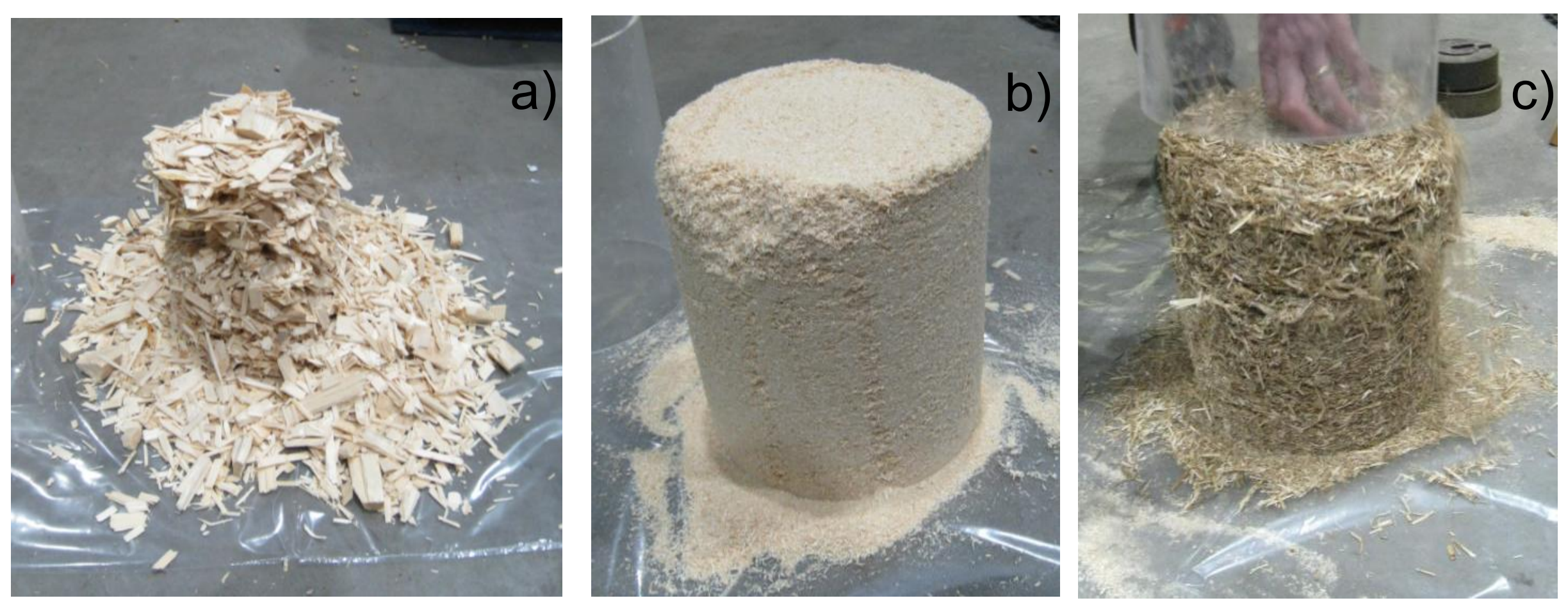

a) wood chips, b) wood powder, c) reed canary grass 